\title{
Significant contribution of large particles to optical backscattering in the open ocean
}

\author{
G. Dall'Olmo ${ }^{1}$, T. K. Westberry ${ }^{1}$, M. J. Behrenfeld ${ }^{1}$, E. Boss ${ }^{2}$, and W. H. Slade ${ }^{2}$ \\ ${ }^{1}$ Department of Botany and Plant Pathology, 2082 Cordley Hall, Oregon State University, Corvallis, OR 97331, USA \\ ${ }^{2}$ MISC Lab, University of Maine, 458 Aubert Hall, Orono, ME 04469, USA
}

Received: 29 October 2008 - Published in Biogeosciences Discuss.: 8 January 2009

Revised: 15 April 2009 - Accepted: 22 May 2009 - Published: 5 June 2009

\begin{abstract}
The light scattering properties of oceanic particles have been suggested as an alternative index of phytoplankton biomass than chlorophyll- $a$ concentration (chl- $a$ ), with the benefit of being less sensitive to physiological forcings (e.g., light and nutrients) that alter the intracellular pigment concentrations. The drawback of particulate scattering is that it is not unique to phytoplankton. Nevertheless, field studies have demonstrated that, to first order, the particulate beam-attenuation coefficient $\left(c_{p}\right)$ can track phytoplankton biomass. The relationship between $c_{p}$ and the particulate backscattering coefficient $\left(b_{b p}\right)$, a property retrievable from space, has not been fully evaluated, largely due to a lack of open-ocean field observations. Here, we present extensive data on inherent optical properties from the Equatorial Pacific surface waters and demonstrate a remarkable coherence in $b_{b p}$ and $c_{p}$. Coincident measurements of particle size distributions (PSDs) and optical properties of sizefractionated samples indicate that this covariance is due to both the conserved nature of the PSD and a greater contribution of phytoplankton-sized particles to $b_{b p}$ than theoretically predicted. These findings suggest that satellite-derived $b_{b p}$ could provide similar information on phytoplankton biomass in the open ocean as $c_{p}$.
\end{abstract}

\section{Introduction}

Inherent optical properties (IOPs) have been recognized as important tools to study many ecophysiological and biogeochemical oceanic processes at sub-meter spatial scales and at high temporal resolution. For example, IOP data have permitted deriving proxies of phytoplankton cell size (Ciotti et al., 2002) and growth-rate estimates of particulate organic

Correspondence to: G. Dall'Olmo

(giorgiod@science.oregonstate.edu) matter (Siegel et al., 1989; Claustre et al., 1999). Understanding how different types of oceanic particles affect the bulk inherent optical properties is fundamental for inferring particle dynamics and ecosystem rates from in-situ and satellite-inverted IOPs.

The contribution of oceanic microorganisms to IOPs such as the particle beam-attenuation and scattering coefficients $\left(c_{p}\right.$ and $b_{p}$, respectively) have been investigated rather extensively by means of flow cytometry (Durand and Olson, 1996; Chung et al., 1996, 1998; Claustre et al., 1999; Green et al., 2003; Oubelkheir et al., 2005; Grob et al., 2007). Typically, the concentrations, sizes, and refractive indices of specific groups of microorganisms were estimated and then their contribution to $c_{p}$ calculated.

In some of these investigations, the observed microorganisms (autototrophs and heterotrophs) accounted for a rather constant fraction of $c_{p}$, while the remaining fraction of $c_{p}$ was attributed to an unmeasured particle pool referred to as "detritus" (Chung et al., 1996, 1998; Claustre et al., 1999; Oubelkheir et al., 2005). A corollary of these findings is that it should be possible to estimate the attenuation by microorganisms from bulk $c_{p}$ measurements (Chung et al., 1998). By further considering that the biomass of autotrophic and heterotrophic microbes covary in the open-ocean over large scales (Cole et al., 1988; Gasol and Duarte, 2000), we can then conclude that, to first order, bulk $c_{p}$ should be proportional to phytoplankton beam attenuation $\left(c_{\phi}\right)$.

Other studies estimated that phytoplankton accounted for up to 50-60\% of $c_{p}$ (Durand and Olson, 1996; Chung et al., 1996; Green et al., 2003). In addition, Durand and Olson (1996) showed that most of the diel variations in bulk $c_{p}$ could be attributed to variations in phytoplankton $c_{p}$. Thus, in these investigations a first order correlation emerged directly between bulk $c_{p}$ and phytoplankton beam attenuation coefficient.

Published by Copernicus Publications on behalf of the European Geosciences Union. 
A validation of the above estimates was only presented by Green et al. (2003) who favorably compared the reconstructed total particulate scattering signals to independently measured bulk $b_{p}$ (which dominates $c_{p}$ ). Indeed, most of the aforementioned investigations adopted different hypotheses to which the calculated scattering cross-sections are strongly dependent: for example, some studies employed forward scattering measurements to obtain particle sizes (Durand and Olson, 1996; Chung et al., 1998; Green et al., 2003; Grob et al., 2007), while others assumed fixed sizes for a given particle type (Chung et al., 1996; Claustre et al., 1999; Oubelkheir et al., 2005). Thus, it is unclear if the differences in the reported contributions of microorganisms to bulk $c_{p}$ were real and due to variations in the geographic regions, or biased because of the the assumptions regarding size and scattering theory used to retrieve $c_{p}$.

Regardless, we have explained why a correlation between $c_{p}$ and phytoplankton biomass (the first order driver of $c_{\phi}$ ) is expected. Certainly this global correlation may break down at more regional scales, but it provides a way to derive phytoplankton biomass alternative to chlorophyll- $a$ concentration (chl- $a$ ). Indeed, despite its historical acceptance as an index of phytoplankton biomass, chl- $a$ is also strongly influenced by physiological forcing such as light availability and nutrient stress (e.g., Geider et al., 1998). The chl- $a: c_{p}$ ratio should thus reveal these physiological variations by removing the biomass dependence from chl- $a$.

To test this hypothesis, Behrenfeld and Boss (2003) analyzed existing time-series of data and found a correlation between chl- $a$-normalized $c_{p}$ and a ${ }^{14} \mathrm{C}$-based photoacclimation index. These investigators later assumed that $c_{p}$ correlates with the particulate backscattering $\left(b_{b p}\right)$ in the open ocean and derived relationships between satellite-based chl$a: b_{b p}$ and environmental variables that closely mimic the chl$a$-to-carbon ratios measured in laboratory cultures of phytoplankton (Behrenfeld et al., 2005). Thus, these studies support the hypothesis that phytoplankton biomass correlates with $c_{p}$ and $b_{b p}$ in the open ocean.

This new scattering-based approach for interrogating variability in phytoplankton ecophysiology from space still has a critical knowledge gap: it is not yet clear the extent to which a direct connection exists between $c_{p}$ and $b_{b p}$ at the global scale. An exception is the recent analysis by Huot et al. (2008) that reported strong correlations in the South Pacific between both $b_{p}$ or $b_{b p}$ and chl- $a$ and, by extension, between $b_{p}$ and $b_{b p}$. Note that $b_{p}$ and $c_{p}$ are here used interchangeably because $b_{p}$ dominates $c_{p}$ in the open ocean (e.g., Loisel and Morel, 1998).

Despite this recent study, the relationship between $c_{p}$ and $b_{b p}$ is not well understood in the open ocean, mostly due to the lack of coincident $c_{p}$ and $b_{b p}$ measurements. Theoretical simulations for homogeneous spherical particles (i.e., Mie theory) predict that $c_{p}$ and $b_{b p}$ are influenced by particles belongings to different size fractions (Morel and Ahn, 1991; Stramski and Kiefer, 1991). As a specific example, Mie theory predicts that $50 \%$ of $b_{p}$ is due to particles $<3.2 \mu \mathrm{m}$, while $50 \%$ of $b_{b p}$ is from particles $<0.2 \mu \mathrm{m}$, if low refractive index (phytoplankton-like) homogeneous spherical particles that follow a power-law size distribution with exponent of -4 are considered (Stramski and Kiefer, 1991). Thus, the relationship between $b_{b p}$ and phytoplankton biomass may not be as strong as for $c_{p}$ and would depend on the conserved nature of the particle size distribution (PSD) (i.e., that small particles covary with phytoplankton-sized particles).

One of the problems with using Mie theory to simulate backscattering coefficients is that oceanic microorganisms are not homogenous spheres. Theoretical models that account for internal structure and non-sphericity of the particles predict backscattering coefficients significantly higher (up to an order of magnitude) than those expected for equivalent homogeneous spheres (Meyer, 1979; Bohren and Singham, 1991; Kitchen and Zaneveld, 1992; Quirantes and Bernard, 2004; Clavano et al., 2007). Moreover, direct laboratory measurements of the backscattering coefficient (or the volume scattering function) of phytoplankton cultures are also in disagreement with predictions based on the homogeneous spherical model. For example, Vaillancourt et al. (2004) showed that observed backscattering efficiency factors could be reproduced by Mie theory only by using refractive indices significantly higher than those expected for phytoplankton. Similarly, Volten et al. (1998) concluded that theoretical predictions could not achieve a "good agreement" with their measured volume scattering functions because these predictions are "too steep" in the forward direction (i.e., the backscattering ratio $b_{b p}: b_{p}$ predicted by Mie theory is too small). Quinby-Hunt et al. (1989) demonstrated that the elements of the scattering matrix measured on a Chlorella culture could be satisfyingly reproduced only by a coatedsphere model. When the volume-average of the refractive indices fitted for the coating and for the core of the modeled cell was used as input to the homogeneous spherical model, backscatter was overestimated by a factor 3 . Furthermore, Stramski and Piskozub (2003) indirectly determined the backscattering ratios of two species of marine phytoplankton to be between at least three and ten fold larger than those predicted by Mie theory. The above comparisons between theory and observations were conducted by independent researchers and provide strong evidence that the homogeneous spherical model is insufficient to accurately model the shape of the volume scattering function and the backscattering coefficient of phytoplankton cells.

On the other hand, other investigators have estimated the backscattering of phytoplankton and bacteria by using Mie theory and measuring the volume scattering function over a limited range of backward angles (Morel and Ahn, 1991; Ahn et al., 1992). Results from these studies were in good agreement with the homogeneous spherical model and presented backscattering coefficients for phytoplankton too small to account for the bulk $b_{b p}$ measured in the open ocean. These authors thus concluded that a large fraction of 


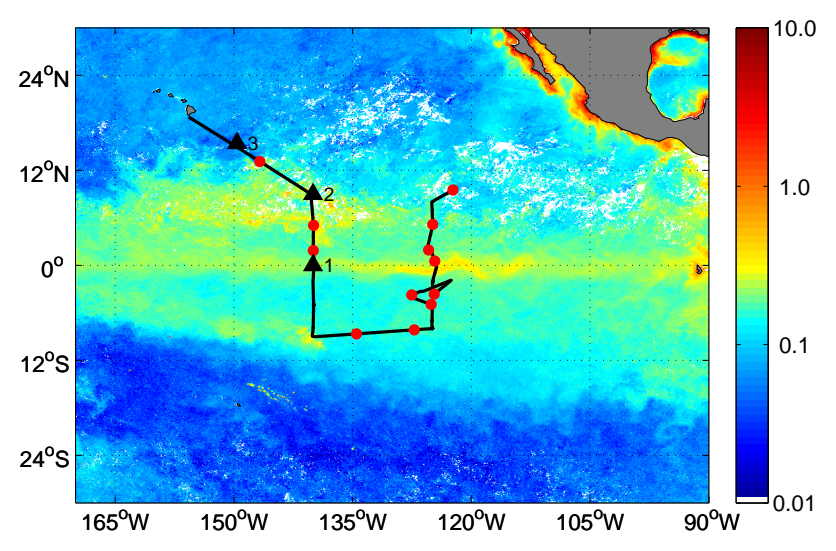

Fig. 1. SeaWiFS chlorophyll- $a$ map (units of $\mathrm{mg} \mathrm{m}^{-3}$ ) for May 2007 showing the cruise track and the locations of the 3- $\mu \mathrm{m}$ filtrations (red circles) and of the fractionation experiments (black triangles with corresponding experiment number). Clouds and land are represented in white and gray, respectively.

the measured bulk $b_{b p}$ must be due to a group of particles in the submicron size range that has not been well characterized and that seems to be mostly composed of detritus and colloids. Stramski and Kiefer (1991) modeled microorganisms as homogeneous spherical particles and came to similar conclusions. Thus, contrasting results have been presented so far with respect to the backscattering properties of oceanic microorganisms (Stramski et al., 2004).

The current study focuses on the relationship between $c_{p}$ and $b_{b p}$ in open-ocean surface waters. We find a close correlation between $c_{p}$ and $b_{b p}$ using high temporal resolution $b_{b p}$ and $c_{p}$ data collected along a $9000 \mathrm{~km}$-long transect. Backscattering from particles smaller than $0.2 \mu \mathrm{m}$ was negligible and, as a consequence, backscattering from particles in the phytoplankton size range $(0.5-20 \mu \mathrm{m})$ contributed a significantly greater proportion of the bulk $b_{b p}$ than predicted by Mie theory. These findings and the relatively constant shape of the particle size distribution in open-ocean environments provide supporting evidence to the use of $b_{b p}$ as an alternative to chl- $a$ for quantifying phytoplankton biomass from space.

\section{Methods}

\subsection{Flow-through measurements}

Flow-through measurements were conducted on the clean seawater supply (intake at $3 \mathrm{~m}$ depth) of the R.V. Ka'imi Moana during a Tropical Atmosphere Ocean cruise from 8 May to 5 June 2007. The cruise track covered three sides of a rectangle that approximately spanned from $125^{\circ} \mathrm{W}$ to $140^{\circ} \mathrm{W}$ and between $10^{\circ} \mathrm{S}$ and $10^{\circ} \mathrm{N}$. During the final leg of the cruise, the ship journeyed over a transect from $10^{\circ} \mathrm{N}$ $140^{\circ} \mathrm{W}$ to the Hawaiian islands (Fig. 1). Temperature, salinity and position were recorded by the ship's underway system. To remove bubbles, the seawater supply was plumbed through two vortex debubblers in series (model VDB-1G, diameter of about $5 \mathrm{~cm}$, Stony Brook, NY, USA). Sample water was then distributed to the optical instruments. To account for the dissolved signals, instrumental drifts, and biofouling, a custom-made automatic valve directed the bulk seawater through a $0.2-\mu \mathrm{m}$ Cole Parmer nylon cartridge filter, for ten minutes every hour. On twelve occasions along the cruise, the sample water arriving from the debubblers was manually diverted through a 3.0- $\mu \mathrm{m}$ Cole Parmer nylon cartridge filter for at least $20 \mathrm{~min}$ to measure the contribution from particles smaller than $3 \mu \mathrm{m}$ to the bulk inherent optical properties.

Beam-attenuation coefficients were measured at 526 and $650 \mathrm{~nm}$ by two $25-\mathrm{cm}$ WET Labs C-star transmissometers (sampling rate $5.8 \mathrm{~Hz}$ ). The wavelengths corresponding to the emission maxima of the light sources, $\lambda_{c}$, of each transmissometer were determined after the cruise by using a spectrally calibrated radiometer (OceanOptics USB2000) and were found to be shifted from the manufacturer declared values by -6 and $-10 \mathrm{~nm}$, respectively. Hyperspectral beam attenuation and absorption coefficients were also measured between 400 and $750 \mathrm{~nm}$ by a $25-\mathrm{cm}$ WET Labs spectral absorption and attenuation meter (AC-s, sampling rate $3.9 \mathrm{~Hz}$ ).

The volume scattering function at a central angle of about $117^{\circ}, \beta\left(117^{\circ}\right)\left(\mathrm{m}^{-1} \mathrm{sr}^{-1}\right)$, was measured by a WET Labs ECO-BB3 Measurement Sensor at three wavelengths (470, 526 and $656 \mathrm{~nm}$, sampling rate $1 \mathrm{~Hz}$ ). The reported $\lambda_{c}$ for the backscattering meter were also determined spectroradiometrically and were found to differ from the stated WET Labs values by $0,-6$, and $-4 \mathrm{~nm}$, respectively, after accounting for the spectral responses of their detectors and interference filters (e.g., Twardowski et al., 2007). Instrument gains were increased by the manufacturer before the cruise to measure the low $\beta\left(117^{\circ}\right)$ values expected in the Equatorial Pacific waters and in the oligotrophic North Pacific Subtropical Gyre. The instrument was operated in a custom-made flow-through chamber. Briefly, the instrument light sources illuminated the water sample from the bottom of the chamber, thus avoiding accumulation of occasional bubbles on the optical surface. In addition, a baffle in the chamber prevented unwanted photons from reaching the instrument detector. The internal surfaces of the chamber and the baffle were made of black glossy high density polyethylene that minimized diffuse reflectance from the chamber walls (and thus retro-diffusion of unwanted photons into the detector field-of-view, Breneman, 1981 ). Most of the photons were reflected by the chamber walls in the direction opposite to the instrument, thus favoring their absorption by multiple interactions with the chamber sides and baffle. The chamber volume (about 8.71) was conservatively chosen to minimize back-reflections from the chamber sides. A plug (14-cm in diameter) on one of the sides of the chamber was used for installing the instrument and daily cleaning. 
Laboratory experiments were carried out to assess the backscattering signal, $b_{b}$,wall, contributed by reflections off the chamber walls. $b_{b}$,wall was determined in replicate experiments by measuring the particulate backscattering of reverse-osmosis water that was recirculated through a $0.2 \mu \mathrm{m}$ Cole Parmer nylon cartridge filter for about two hours. The

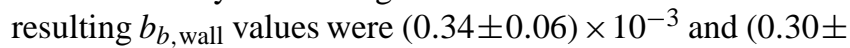
$0.05) \times 10^{-3} \mathrm{~m}^{-1}$ for the blue and green channels, respectively. We note that such determination might be an overestimate of $b_{b}$,wall because the $0.2 \mu \mathrm{m}$ filtration may leave colloidal particles in the water sample.

$b_{b \text {,wall }}$ should theoretically decrease when natural samples are measured in the flow-through chamber because, as the attenuation by particles or other dissolved substances increases, the photons traveling from the instrument lightsource to the chamber wall have a smaller probability of returning to the detector. This decrease in $b_{b \text {,wall }}$ however should be limited since the pathlength covered by these photons is relatively short. We tested this hypothesis by comparing the $b_{b \text {,wall }}$ measured in reverse-osmosis water with that measured when the total absorption coefficient was raised to about 2.0 and $2.2 \mathrm{~m}^{-1}$, in the blue and green channels, respectively, by adding a $0.1 \mu \mathrm{m}$-filtered solution of cobalt chlorine. Under these relatively high absorption values, the measured decreases in $b_{b}$, wall were practically insignificant: $(0.046 \pm 0.046) \times 10^{-3}$ and $(0.030 \pm 0.030) \times 10^{-3} \mathrm{~m}^{-1}$ in the blue and green channels, respectively. It was therefore decided to consider the values of $b_{b \text {, wall }}$ measured in the laboratory to be constant over the range of optical properties encountered during this study.

Raw digital counts were converted into $b_{b p}$ values by means of the following equation:

$b_{b p}=2 \pi \chi_{p}\left[S(C-D)-\beta_{s w}\right]-b_{b, \text { wall }}$

where $S(C-D)$ and $\left[S(C-D)-\beta_{s w}\right]$ are the total and particle volume scattering functions, $\beta$ and $\beta_{p}$, respectively; $\chi_{p}$, taken equal to 1.1 , is the factor used to convert the $\beta_{p}$ at a central angle of $117^{\circ}$ into $b_{b p}$ (Boss and Pegau, 2001); $S$ is the scaling factor determined through a serial dilution with calibrated beads; $C$ are the digital counts; $D$ are the dark counts measured when no light reaches the detector, and $\beta_{s w}$ is the volume scattering function of pure seawater at the same wavelength and angle at which the BB3 meter measures. To estimate $\beta_{s w}$, the models by Zhang and $\mathrm{Hu}$ (2009) and Zhang et al. (2009) with a depolarization ratio of 0.039 were adopted throughout this study.

The combined experimental uncertainty in $b_{b p}$ was calculated by applying the standard law for the propagation of uncertainty (BIPM and ISO, 1995) to Eq. (1) and assuming uncorrelated uncertainties. The uncertainties of each term of Eq. (1) used in these calculations are reported in Table 1; their median percent squared contributions to the combined $b_{b p}$ uncertainty as well as their median absolute contributions are presented in Table 2.
Table 1. Experimental uncertainties of each term of Eq. (1) used to compute the combined experimental uncertainty of $b_{b p}$ as a function of wavelength. Units of absolute uncertainties are the same as those reported in the text for the corresponding variables.

\begin{tabular}{cccl}
\hline Variable & \multicolumn{2}{c}{ Uncertainty } & Reference \\
& $470 \mathrm{~nm}$ & $526 \mathrm{~nm}$ & \\
\hline$\chi_{p}$ & $4.4 \%$ & $4.4 \%$ & Boss and Pegau (2001) \\
$S$ & $1.2 \times 10^{-7}$ & $0.31 \times 10^{-7}$ & measured \\
$C$ & 1.5 & 2 & measured \\
$D$ & 1 & 1 & measured \\
$\beta_{s w}$ & $2.24 \%$ & $2.24 \%$ & Zhang et al. (2009) \\
$b_{b, \text { wall }}$ & $6.4 \times 10^{-5}$ & $5.1 \times 10^{-5}$ & measured \\
\hline
\end{tabular}

Table 2. Uncertainty budget for $b_{b p}$ based on the values presented in Table 1 and on all BB3 measurements collected during the cruise. Numbers represent the median values of the squared percent contributions, $\sigma_{\text {rel }}^{2}$ (unitless), and the median absolute contributions, $\sigma$ $\left(\mathrm{m}^{-1}\right)$, by each input variable to the combined experimental uncertainty in $b_{b p}$ as a function of wavelength.

\begin{tabular}{ccccc}
\hline Variable & \multicolumn{2}{c}{$\sigma_{\text {rel }}^{2}$} & \multicolumn{2}{c}{$\sigma \times 10^{-4}$} \\
& $470 \mathrm{~nm}$ & $526 \mathrm{~nm}$ & $470 \mathrm{~nm}$ & $526 \mathrm{~nm}$ \\
\hline$\chi_{p}$ & 11 & 15 & 0.41 & 0.35 \\
$S$ & 24 & 4 & 0.62 & 0.17 \\
$C$ & 24 & 37 & 0.62 & 0.55 \\
$D$ & 11 & 9 & 0.42 & 0.27 \\
$\beta_{s w}$ & 9 & 6 & 0.37 & 0.23 \\
$b_{b, \text { wall }}$ & 26 & 32 & 0.64 & 0.51 \\
\hline
\end{tabular}

During the field study, data from all instruments were time stamped and merged using a WET Labs Data Handler-4. To minimize biofouling effects, all instruments as well as the backscattering flow-chamber were thoroughly cleaned with a mild detergent, diluted ethanol (for glass surfaces only), and deionized water usually every day, and on a few occasions every two days. The $0.2-\mu \mathrm{m}$ and $3-\mu \mathrm{m}$ cartridge filters were replaced weekly.

\subsection{Particle size distribution measurements}

Measurements of particle size distributions were conducted in 1-ml triplicates with a Coulter Counter Multisizer-3 fitted with a 70- $\mu \mathrm{m}$ aperture tube (which resulted in equivalent spherical diameters, ESD, distributed in 256 size bins between 1.4 and $42 \mu \mathrm{m}$ ) at 71 locations along the cruise track. These triplicate measurements were then averaged to reduce the statistical noise. To further reduce noise, the number of size bins was reduced to 22 by aggregating data over larger bin sizes. Specifically, beginning from the smallest size bin, we aggregated counts of the first three original bins into a new bin and set the new central size to the weighted (by the 
counts in each bin) average of the central sizes of three original bins. We then repeated the same procedure to compute the second larger new bin, but we aggregated counts over the following 4 original bins. Similarly, for the third new bin we aggregated data over the following 5 original bins. We continued this aggregation procedure by incrementing by one the number of original bins over which data were aggregated at each new aggregated bin. In this way, the new bins at the largest sizes were derived by aggregating the largest number of original bins. The particle numbers $N_{i}$ measured by a Coulter counter in each size bin approximately follow a Poisson distribution and their standard deviation is equal to $N_{i}^{0.5}$. Thus, by accumulating counts over the three replicates and over the larger bins, we were able to significantly increase the number of particles per bin and thus the precision of our measurements. The aggregated PSDs were characterized by coefficients of variation at most of $10 \%$ for bin sizes smaller than $5 \mu \mathrm{m}$ and in all cases $<30 \%$ and typically $<15 \%$ for bins smaller or equal than $8 \mu \mathrm{m}$. Obviously, the aggregation of the original bins into new ones spanning larger sizes causes a coarsening of the size resolution. However, since the original number of bins was rather large, the number of new aggregated bins was 14 for sizes spanning from 1.4 to $8 \mu \mathrm{m}$ and thus satisfactory for the purposes of our analysis.

A power law was fitted to the differential particle size distributions using data points with ESD between 2 and $8 \mu \mathrm{m}$ and a non-linear fitting routine (Boss et al., 2001). The lower limit of $2 \mu \mathrm{m}$ was selected to avoid peaks in the PSDs that at times were observed around $1.5 \mu \mathrm{m}$. The upper limit was chosen based on the above estimate of precision (i.e., to only use data with a precision better than 15\%). We compared the PSD exponents resulting from the fits on the accumulated replicates and on the accumulated replicates that had also been aggregated in larger bins. We found that the mean PSD exponents in the former and latter cases were not statistically different, at the $95 \%$ confidence level. This is probably because the information content of the more noisy, but more numerous data is approximately the same as that of the less noisy, but fewer data aggregated over larger size bins. Results reported hereafter are those referring to the averaged replicates without accumulation of counts over larger bins.

As an additional consistency check, the efficiency factor for attenuation $\left(Q_{c}\right)$ for the average particle was computed as the ratio of concurrent bulk $c_{p}$ values (as measured by the C-star transmissometer at $526 \mathrm{~nm}$, see below) and total geometric cross-sections derived from the PSDs. The median $\left( \pm \sigma_{p}\right) Q_{c}$ was $2.23 \pm 0.36$ and thus in agreement with theoretical predictions (Hulst van de, 1957, Fig. 32) and indicative of consistent PSD and $c_{p}$ measurements.

\subsection{Pigment concentrations}

Pigment concentrations were measured in several ways. Seawater samples $(500 \mathrm{ml})$ were concentrated on $25-\mathrm{mm}$ Whatman GF/F filters and extracted in $90 \%$ acetone for 24 to
$36 \mathrm{~h}$ in a freezer. The concentration of chlorophyll- $a$ (chla) was determined fluorometrically (Turner Designs) following the acidification method (Strickland and Parsons, 1972). Similarly, size-fractionated chl- $a$ was measured after filtering $250 \mathrm{ml}$ of sample on $1-\mu \mathrm{m}$ and $5-\mu \mathrm{m}$ Nuclepore polycarbonate filters. An additional 21 of seawater were filtered on Whatman GF/F filters and stored in liquid nitrogen for high performance liquid chromatography (HPLC) analysis in the laboratory (Hooker et al., 2000; Van Heukelem and Thomas, 2001). Total chlorophyll- $a$ concentration, TChl- $a$, was calculated by summing the contributions of monovinylchl- $a$, divinyl-chl- $a$ (DivChl- $a$ ), and chlorophyllide $a$. Chl- $a$ was also computed by exploiting the red absorption band of the highly AC-s $a_{p}$-spectra (see below). Specifically, chl$a$ was calculated from the particulate absorption line height around $676 \mathrm{~nm}$ as chl- $a^{\mathrm{ACs}}=\left[a_{p}(676)-39 / 65 a_{p}(650)-\right.$ 26/65a $a_{p}$ (715)]/0.014 (e.g., Boss et al., 2007).

An intercalibration of the three different methods for determining chl- $a$ was achieved by linearly regressing fluorometric chl- $a$ and chl- $a^{\mathrm{ACs}}$ against HPLC-derived TChl- $a$. The results of these regressions demonstrated that the intercepts of the above relationships were negligible while the slopes were not significantly different from 1: $1.13(99 \%$ confidence interval: $0.9-2.4)$ and 1.13 (99\% confidence interval: $0.9-1.2$ ), for the fluorometric chl- $a$ and chl- $a^{\mathrm{ACs}}$, respectively. The medians of the relative residuals were not significantly different from zero (at the $99 \%$ confidence level) and their precisions (computed as half the difference between the 84th and 16th percentile, henceforth abbreviated as $\sigma_{p}$ ) were $10.8 \%$ and $10.9 \%$ for the fluorometric chl- $a$ and chl- $a^{\mathrm{ACs}}$, respectively. Thus, chl- $a^{\mathrm{ACs}}$ and fluorometric chl- $a$ were in agreement with TChl- $a$ and no additional correction was applied.

\subsection{Flow-through data processing}

\subsubsection{C-star and AC-s meters}

Optical measurements from all instruments were averaged into 1-min time intervals before further processing. To compute particulate beam attenuation and absorption coefficients ( $c_{p}$ and $a_{p}$, respectively), the median values of the beam attenuation and absorption coefficients measured during each of the $0.2-\mu \mathrm{m}$ filtration times were linearly and piecewise interpolated between hours and subtracted from the bulk measurements. This procedure allowed us to determine calibration-independent particulate beam-attenuation and absorption coefficients, with the uncertainties determined mostly by the instrument precision (Boss et al., 2007). AC-s $c_{p}$ and $a_{p}$ spectra were further processed to 1) remove a spurious spectral step that was at times observed in the green spectral region (corresponding to the discontinuity in the AC-s filter wheel; Zaneveld, personal communication), 2 ) remove the scattering error from the $a_{p}$ data (method \#3, Zaneveld et al., 1994) and 3) account for variations in sample 
temperature between consecutive $0.2-\mu \mathrm{m}$ filtered data points. Finally, the particle scattering coefficient, $b_{p}$, was computed as the difference between $c_{p}$ and $a_{p}$.

$\mathrm{C}$-star measurements were processed as for the AC-s to obtain independent $c_{p}$ values. However, the correction for variation in sample temperature was not applied because the temperature dependence of water absorption around $650 \mathrm{~nm}$ can be considered negligible (Sullivan et al., 2006).

\subsubsection{Backscattering coefficients}

The BB3 meter was calibrated by the manufacturer before the cruise and by the authors after the cruise, to obtain the scaling factors required to convert the digital counts into physical values of $\beta\left(\lambda_{c}, 117^{\circ}\right)$. Both calibrations were completed using $2-\mu \mathrm{m}$ beads (Duke Scientific) following established protocols (Moore et al., 2000). The relative difference between the pre- and post-cruise scaling factors was found to be insignificant for the blue and green channels $(-4 \pm 5 \%$ and $-1 \pm 4 \%$, respectively), but a significant positive $15 \pm 2 \%$ deviation was found for the red channel that could not be attributed to any specific event during the cruise or the shipment of the meter. In addition, $b_{b p}$ values in the red channel appeared to be contaminated by chl- $a$ fluorescence (not shown). Thus, only the blue and green channels of the BB3 were used in the following analysis. The scaling factors were computed as the mean of the pre- and post-cruise measurements. The resulting values and their combined experimental uncertainties (BIPM and ISO, 1995) were: $(6.02 \pm 0.12) \times$ $10^{-6}$ and $(3.968 \pm 0.031) \times 10^{-6} \mathrm{sr}^{-1}$ count $^{-1}$ for the blue and green channels, respectively. Dark readings were determined every two days by covering the detectors with black tape and submerging the instrument in water. The median values $\left( \pm \sigma_{p}\right)$ were found to be $53 \pm 1$ and $56 \pm 1$ counts for the blue and green channels, respectively. Particle backscattering coefficients were finally calculated from Eq. (1) using the above derived scaling factors and dark counts. Combined median relative uncertainties in $b_{b p}$ were about $17 \%$ and $14 \%$ for the blue and green channels, respectively, with maximum uncertainties, found in the most oligotrophic waters, of about $32 \%$ and $27 \%$, respectively.

The turnover time of seawater in the backscattering flowthrough chamber was longer than the 10 min during which the seawater supply was diverted through the $0.2-\mu \mathrm{m}$ cartridge filter. Thus, the $b_{b p}$ measured during these $10 \mathrm{~min}$ never reached a constant minimum value, although it showed the characteristic exponential decay and it decreased by about $75 \%$ (Fig. 2a, filled circles). Similarly, measured $b_{b p}$ values exhibited a lag of about $10 \mathrm{~min}$ before reaching the bulk $b_{b p}$ signal upon returning the seawater flow to its original, unfiltered path (Fig. 2a, pluses after the filled circles). In addition, the first minute of $0.2-\mu \mathrm{m}$ filtered data was often noisy. Thus, the first point of the $0.2-\mu \mathrm{m}$ filtration period, as well as the $10 \mathrm{~min}$ of data following the filtration were removed from the analysis (Fig. 2, pluses). The re-
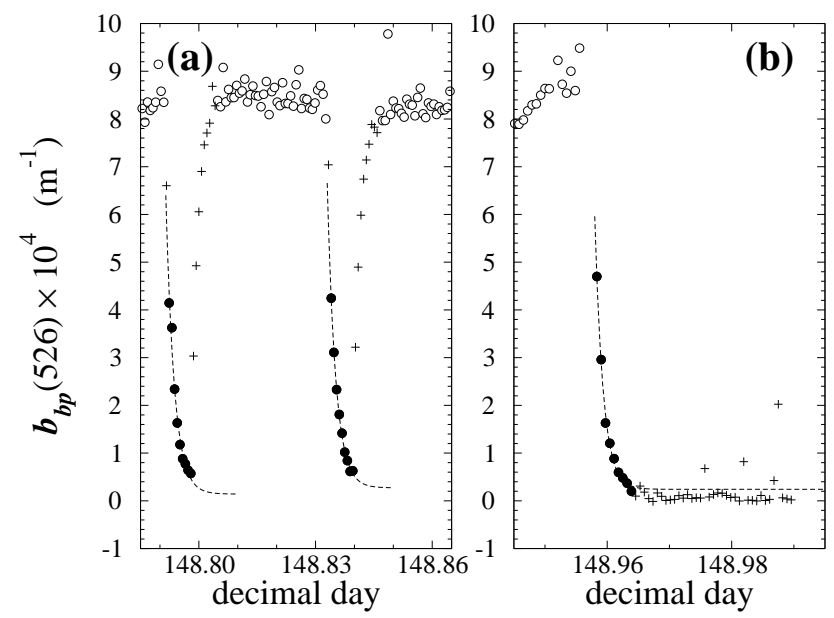

Fig. 2. (a) Example showing bulk $b_{b p}$ measurements used for the analysis (open circles) as well as data collected during the $0.2-\mu \mathrm{m}$ filtration period (filled circles) that were fitted (dashed line) to derive the $0.2-\mu \mathrm{m}$ filtered $b_{b p}(<0.2 \mu \mathrm{m})$ value (obtained as the asymptotic value approached by the dashed line). Pluses indicate data that were excluded from the analysis. (b) $b_{b p}$ data from the 50-min 0.2$\mu \mathrm{m}$ filtration experiment comparing the asymptotic value extrapolated from the fit to the measured $b_{b p}(<0.2 \mu \mathrm{m})$.

maining values were used to estimate bulk $b_{b p}$ (Fig. 2a, empty circles). To obtain the "true" backscattering value for the $0.2-\mu \mathrm{m}$ filtered sample, $b_{b p}(<0.2 \mu \mathrm{m})$, the $b_{b p}$ values measured during the $0.2-\mu \mathrm{m}$ filtered measurements, $b_{b p}(t)$, were fitted to the following relation $b_{b p}(t)=b_{b p}(<0.2 \mu \mathrm{m})+$ $b_{b p}\left(t_{0}\right) \exp \left[-s\left(t-t_{0}\right)\right]$, where $t_{0}$ is the first point of the $0.2-$ $\mu \mathrm{m}$ filtered data used for the fit and $s$ is the decay constant that is proportional to the ratio of the seawater flow rate to chamber volume (Fig. 2, dashed lines). The ratio of the extrapolated $b_{b p}(<0.2 \mu \mathrm{m})$ to the last point of the $0.2-\mu \mathrm{m}$ filtered $b_{b p}$ had a median value $\left( \pm \sigma_{p}\right)$ of $0.85 \pm 0.09$, suggesting that the $0.2-\mu \mathrm{m}$ filtration time was generally long enough to flush out most of the particles from the chamber. On one occasion, the seawater supply was manually diverted through the $0.2-\mu \mathrm{m}$ filter for about $50 \mathrm{~min}$ and the $b_{b p}(<0.2 \mu \mathrm{m})$ value extrapolated from the first $9 \mathrm{~min}$ of the filtration period was found to be only $10^{-5} \mathrm{~m}^{-1}$ larger than the measured median $b_{b p}(<0.2 \mu \mathrm{m})$ (Fig. $\left.2 \mathrm{~b}\right)$ supporting our extrapolation procedure.

\subsection{3 $\chi_{p}$ factor}

The $\chi_{p}\left(117^{\circ}\right)=1.1$ adopted in this study was assumed to be independent of wavelength and obtained from theoretical simulations and experimental field measurements of $\beta_{p}\left(\lambda_{c}, 117^{\circ}\right)$ (Boss and Pegau, 2001). However, this $\chi_{p}\left(117^{\circ}\right)$ value was derived from field and theoretical continuous particle size distributions. In the current study, $\beta_{p}\left(\lambda_{c}, 117^{\circ}\right)$ was often measured on populations of particles 


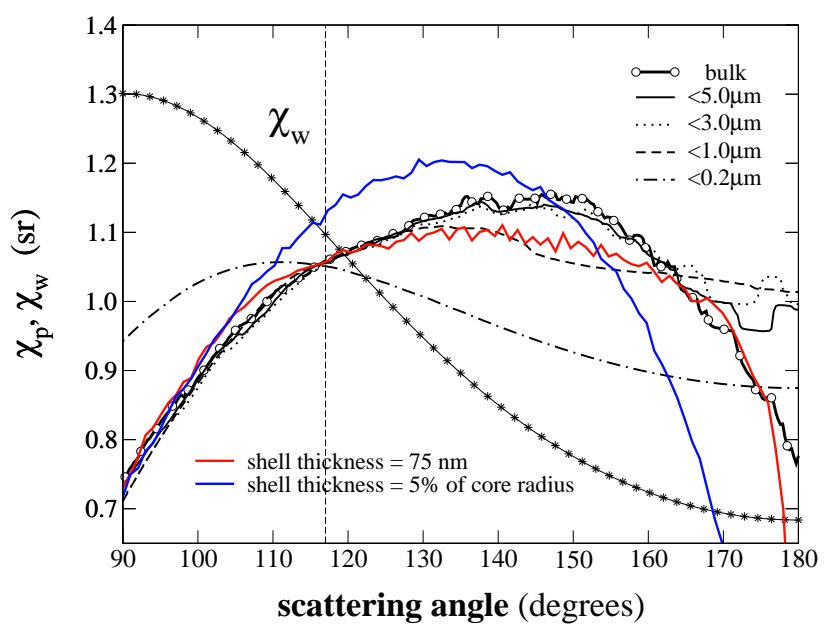

Fig. 3. Median $\chi_{p}$ values computed by re-integrating the theoretical results of Boss and Pegau (2001) using particle size distributions truncated at $0.2,1,3$, and $5 \mu \mathrm{m}$. The median $\chi_{p}$ value for the continuous particle size distributions (indicated as "bulk" in the legend) as well as that for pure water $\left(\chi_{w}\right)$ are also reported for reference. The red and blue lines represent the median $\chi_{p}$ values computed for populations of coated, spherical particles with constant shell thickness of $75 \mathrm{~nm}$ and shell thickness equal to $5 \%$ of the core radius, respectively. The vertical dashed line marks the central angle of the BB3 meter $\left(117^{\circ}\right)$.

that had been truncated by filtration. The applicability of the above $\chi_{p}$ values to truncated particle size distributions was verified by re-examining the theoretical results of Boss and Pegau (2001). Specifically, the particle-specific volume scattering functions resulting from their simulations were reweighted using particle size distributions truncated at $0.2,1$, 3 , and $5 \mu \mathrm{m}$. Figure 3 presents the results of these new integrations and shows that the $\chi_{p}$ values calculated for the truncated particle size distributions do not differ significantly from the value obtained for the continuous particle size distribution around the central angle of the BB3 meter $\left(117^{\circ}\right)$.

While the $\chi_{p}\left(117^{\circ}\right)$ adopted in this study for continuous particle size distributions is in good agreement with the value $(1.08 \pm 0.02)$ obtained by Berthon et al. (2007) from volume scattering functions measured in the North Adriatic Sea, other authors have proposed different values for the $\chi_{p}$ factor. For example, Sullivan et al. (2005) derived a value of $0.90 \pm 0.01$ at $125^{\circ}$ from experimental measurements of the volume scattering function at three angles. On the other hand, Chami et al. (2006) derived a $\chi_{p}\left(117^{\circ}\right)$ factor of $1.29 \pm 0.01$ from in-situ measurements in the Black Sea and showed that phytoplankton cultures can display relatively large interspecific differences in $\chi_{p}$. In addition, the data presented by Chami et al. (2006) suggest that $\chi_{p}$ could be spectrally dependent. Note, however, that by definition the angular mean value of $\chi_{p}^{-1}$ in the backscattering direc- tion has to be 1 . Given that the VSF of natural populations in the back direction is rather flat, large deviation from 1 are not expected. Finally, the absolute values of $b_{b p}$ obtained from Eq. (1) are directly dependent on the adopted $\chi_{p}$ factors. Thus, caution should be exercised when comparing $b_{b p}$ measurements from different investigators.

\subsection{Fractionation experiments}

To assess the contribution of different particle sizes to the measured inherent optical properties, three size-fractionation experiments were conducted at three different stations (see locations in Figs. 1 and 4). Measurements of $c_{p}$ and $b_{b p}$ were conducted on $\sim 201$ of bulk and filtered seawater using AC-s, C-star transmissometers, and BB3 meter in its flow-through chamber. The different size-fractionated samples were obtained by filtering seawater through 0.2- $\mu \mathrm{m}$ Cole Parmer nylon cartridge filters, Whatman GF/F filters (nominal pore size $0.7 \mu \mathrm{m}$, disk diameter $25 \mathrm{~mm}$ ), 1- $\mu \mathrm{m}$ Nuclepore filters (disk diameter $25 \mathrm{~mm}$ ), 3- $\mu \mathrm{m}$ Cole Parmer nylon cartridge filters and 5- $\mu \mathrm{m}$ filters (Cole Parmer polypropylene cartridge filters and also Nuclepore, disk diameter $25 \mathrm{~mm}$ ). For each experiment, instruments were first thoroughly rinsed with filtrate and then optical measurements collected on quiescent samples. A maximum of 11 of seawater was filtered through each disk-filter to minimize clogging. Finally, the variation of the sample water during the course of the experiment was evaluated by including in the error calculation the changes in bulk IOPs measured at the beginning and at the end of each experiment.

\subsection{Flow-through IOP validation}

\subsubsection{Comparison with CTD data}

Flow-through $c_{p}$ data collected by the C-star transmissometer at $650 \mathrm{~nm}$ were compared to the data collected by a different WetLabs C-star transmissometer with light source nominally emitting at $660 \mathrm{~nm}$ installed on the CTD. The spectral emission of this instrument, which failed later in 2007, was not characterized as that for the instrument employed on the flow-through system. The voltages measured by the instrument on the CTD were transformed into $c_{p}$ values by referring them to the voltages measured at $1000 \mathrm{~m}$ (e.g., Loisel and Morel, 1998; Stramski et al., 2008) and the median values of $c_{p}$ values between 3 and $5 \mathrm{~m}$ were used for the comparison with the flow-through data. The range $3-5 \mathrm{~m}$ was selected as a trade-off between avoiding data collected too close to the surface and thus suffering from contamination issues (e.g., bubbles, contamination from the ship) and a depth close to the intake of the flow-through system (about $3 \mathrm{~m}$ ). Deeper values were avoided because the temperature and salinity profiles indicated that at times there was a shallow mixed layer around $10 \mathrm{~m}$. Importantly, no effort was spent in intercalibrating these two instruments, which 

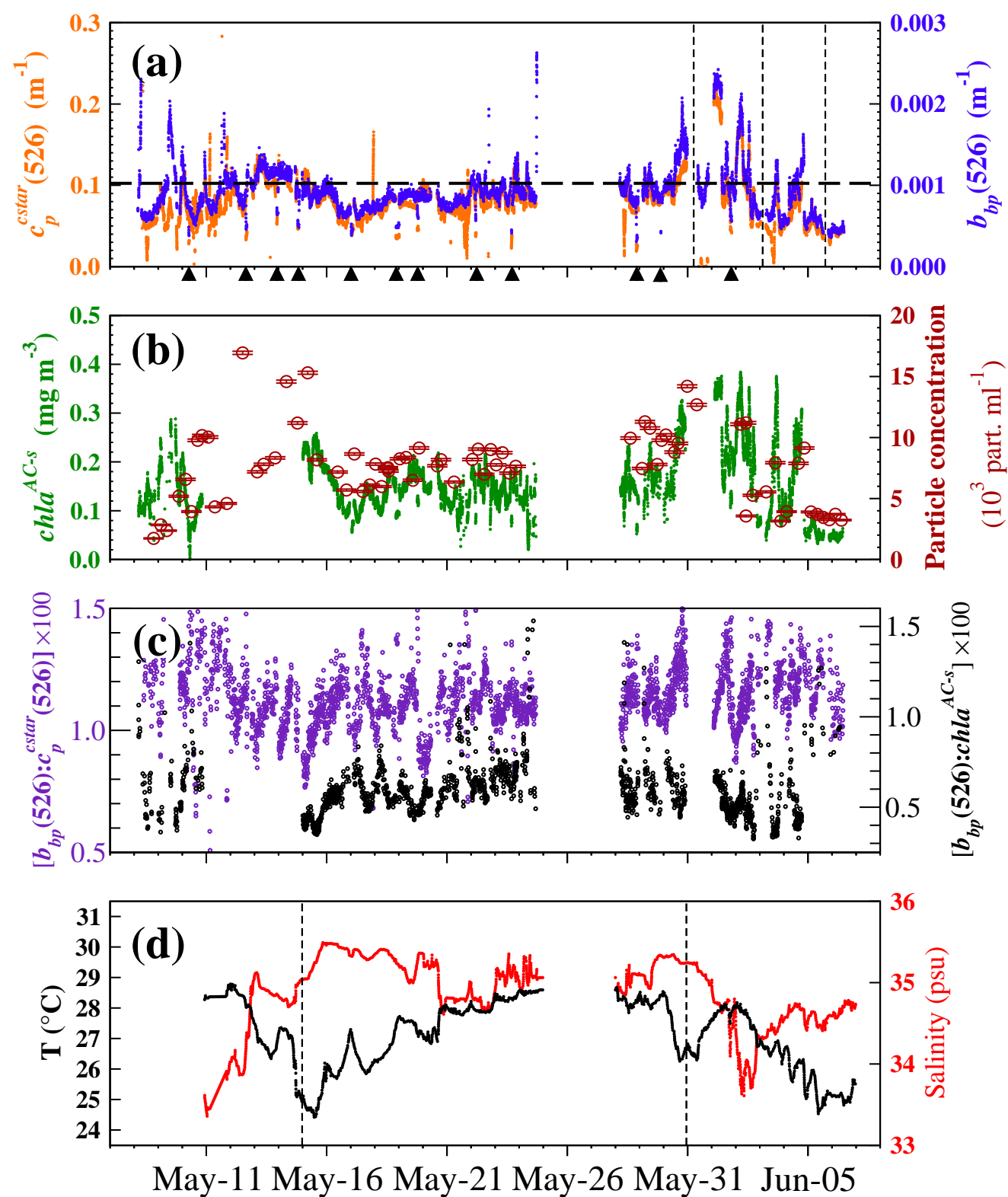

Fig. 4. Time series of data collected along the cruise track. The black triangles and the vertical dashed lines in (a) indicate the locations of the 3- $\mu \mathrm{m}$ filtrations and of the fractionation experiments, respectively. The horizontal dashed line in (a) indicates the backscattering of pure sea water at $526 \mathrm{~nm}$ (Zhang and $\mathrm{Hu}, 2009$; Zhang et al., 2009). The dashed vertical lines in (d) mark the beginning and the end of the two equatorial stations. To remove high frequency noise, all optical data plotted in this figure were filtered as follows: first a median filter (window size of $30 \mathrm{~min}$ ) was applied to each time series and the relative difference $\varepsilon$ between the value of the median filter and the actual data computed; then all points for which $\varepsilon \geq 15 \%$ were excluded from the plot.

were also maintained by different operators. In addition, the calibration coefficient ( $V_{\text {ref }}=4.669$ volts) of the instrument mounted on the CTD and supplied by the manufacturer just before the cruise was significantly higher than the signals measured at $1000 \mathrm{~m}$ which were found to be stable at $V_{1000}=4.5690 \pm 0.0049$ volts . The difference between $V_{\text {ref }}$ and $V_{1000}$ could be an indicator that the instrument mounted on the CTD suffered some damage and/or misalignment dur- ing shipping or installation. Regardless, the comparison between $c_{p}$ data measured on the CTD and in the flow-through system showed that the two data sets were highly correlated $(r=0.99, N=26)$, even though the regression line of the CTD vs. flow-through data had a slope of $1.130 \pm 0.021$ and an intercept of $0.0052 \pm 0.0022 \mathrm{~m}^{-1}$. Thus, in median the $c_{p}$ data collected on the CTD were higher by about $0.0133 \pm 0.0063 \mathrm{~m}^{-1}$. This offset can be related to different 
causes among which differences manufacturing, in the calibration methodology, lack of intercalibration, potential differences in the spectral emission of the two LEDs, and differences in the deployment methodology of the two instruments (open to the environment for the one on the CTD vs. fed with pumped water for that on the flow-through system). In conclusion, despite all the caveats mentioned above, the comparison between the $c_{p}$ values measured on the flowthrough system and on the CTD showed only a minor offset (compare it for example with the bulk $c_{p}$ values in Fig. 4a) and thus support the validity of our flow-through data set.

\subsubsection{Comparison with radiometric data}

Hyperspectral remote-sensing reflectance measurements, $R_{r s}$, were collected at four stations during the cruise by deploying a calibrated Satlantic hyperspectral tethered spectral radiometer buoy (HTSRB). Raw below-surface upward radiance and above-surface downward irradiance data were converted into $R_{r s}$ following Chang et al. (2003). Processing accounted for the depth of the radiance sensor below the sea surface, instrument self-shading errors, and immersion effects.

$R_{r s}$ data at 470 and $526 \mathrm{~nm}$ were compared to $R_{r s}$ values modeled as a function of the coincident IOP data as $R_{r s}=\Re \frac{f}{Q} \frac{b_{b}}{a}$; were $\Re=0.53$ (Gordon, 2005) accounts for the transfer of radiation across the water-air interface; $\frac{f}{O}$ describes the bi-directionality of the underwater light field and was derived from the tables presented in Morel et al. (2002); $b_{b}$ and $a$ are the total backscattering and absorption coefficients, respectively. The measured $a_{p}$ and the pure water absorption by Pope and Fry (1997) were used to compute $a$, but the absorption coefficient of chromophoric dissolved organic matter, $a_{\mathrm{CDOM}}$, also needed to compute $a$, was not available for this cruise. However, $a_{\mathrm{CDOM}}$ spectra collected during TAO cruises that covered the same geographic region during 2005 and 2006 were collected following established protocols (Nelson et al., 2004). The median values $\left( \pm \sigma_{p}\right)$ of $a_{\mathrm{CDOM}}(470)$ and $a_{\mathrm{CDOM}}(526)$ derived during these cruises in the surface Equatorial Pacific waters were $(10.0 \pm 11.5) \times$ $10^{-4}$ and $(1.9 \pm 3.2) \times 10^{-4} \mathrm{~m}^{-1}$, respectively, and were included in the computation of $a$. Modeled remote-sensing reflectances, $R_{r s}^{\bmod }$, were found to be in agreement with the observed ones, $R_{r s}^{\text {obs }}$, with biases (median of percent residuals) of $-10.2 \%$ and $-18.5 \%$ and random uncertainties ( $\sigma_{p}$ of percent residuals) of $11.3 \%$ and $11.9 \%$ in the blue and green channels, respectively (4 observations per channel). Percent residuals were defined as $\left(R_{r s}^{\bmod } / R_{r s}^{\text {obs }}-1\right) \times 100$. Modeled and observed $R_{r s}$ were in good agreement even when the more conservative median $+\sigma_{p}$ values of $a_{\mathrm{CDOM}}$ were used: biases $-13.7 \%$ and $-19.0 \%$ and random uncertainties of $11.6 \%$ and $11.8 \%$ in the blue and green channels, respectively.
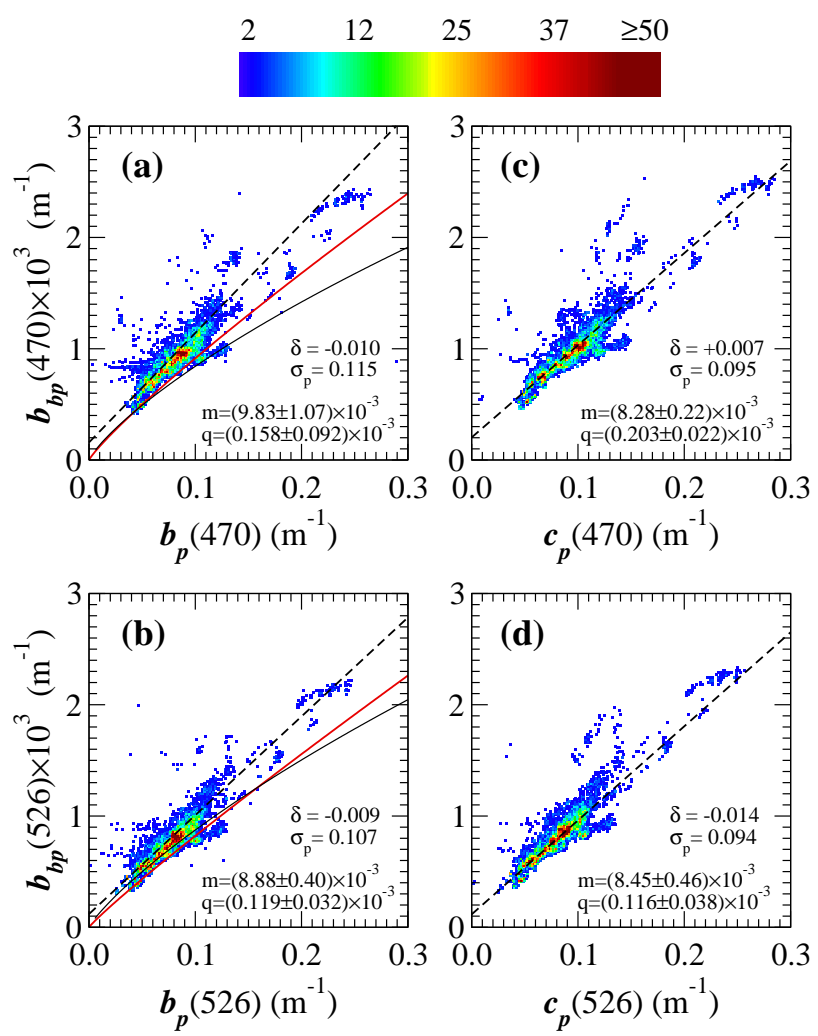

Fig. 5. Bivariate histograms representing the relationships between $b_{b p}$ and $b_{p}(\mathbf{a}, \mathbf{b})$ and $b_{b p}$ and $c_{p}$ (c, d) (from the AC-s) at the central wavelengths of the BB3 meter. The color bar defines the number of data points per bin, $N_{\text {bin }}$. Continuous red lines represent the relationships obtained, after some algebraic manipulation, from the models derived by Huot et al. (2008) from data collected in the South Pacific. Continuous black lines are derived from the models by Morel and Maritorena (2001) and Loisel and Morel (1998). Note we used for both $b_{b p}$ and $b_{p}$ the scattering model by Loisel and Morel (1998) that did not include North Atlantic waters (i.e., subsets $2+3$ of the homogeneous layer). Binned $b_{b p}$ and $c_{p}$ were fitted using a weighted linear regression to the function $b_{b p}=m \times c_{p}+q$ to minimize the leverage of outliers (dashed lines). An iterative technique was used to select the weights which were always integer powers of $N_{\text {bin }}$ : the coefficients of the regression were first determined as the median of 500 bootstrapped samples using as weight $N_{\text {bin }}^{n}$, with $n=0$. Then $n$ was increased by one and the coefficients and their errors recalculated. The iteration was terminated when the changes in both coefficients were smaller than their uncertainties. Reported uncertainties represent the $99 \%$ confidence intervals. The median $(\delta)$ and $\sigma_{p}$ of the relative residuals are also presented as estimates of the bias and precision of the fitted relationships. 


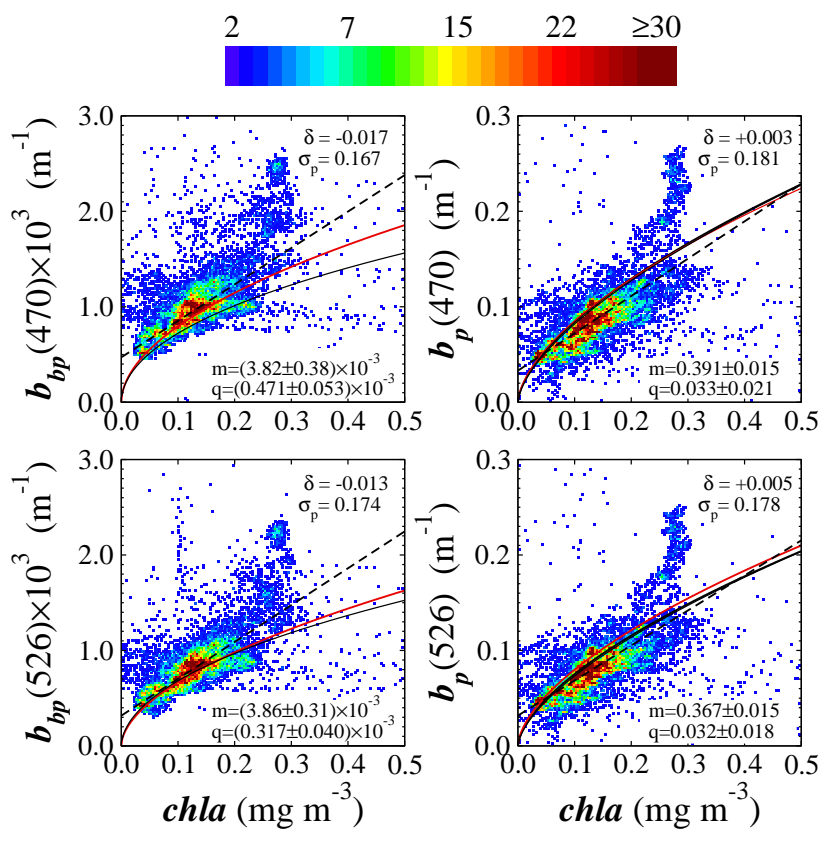

Fig. 6. Bivariate histograms representing the relationships between $b_{b p}$ and chl- $a$ (obtained from the AC-s) and $b_{p}$ and chl- $a$ at 470 and $526 \mathrm{~nm}$. Black lines in (a) and (b) are predictions from the model by Morel and Maritorena (2001). The continuous black line in (c) and (d) are predictions from the models by Loisel and Morel (1998) scaled to the corresponding wavelengths assuming a $\lambda^{-1}$ spectral dependency. The coefficients by Loisel and Morel (1998) that did not include data from the North Atlantic (i.e., subsets $2+3$ of the homogeneous layer) were used. Red lines represent the models derived by Huot et al. (2008). Black dashed lines are linear fits to the data and the text is as in Fig. 5.

\section{Results}

\subsection{Bulk measurements}

Surface particle beam-attenuation and backscattering coefficients showed a remarkable correlation along the whole cruise track (Fig. 4a), and displayed up to 4-fold variations that were related to both the large latitudinal hydrographic features and to finer scale variability in the water masses sampled (Fig. 4d). $b_{b p}$ and $c_{p}$ (or $b_{p}$ ) were tightly correlated both at 470 and at $526 \mathrm{~nm}(r=0.87$ and $r=0.90$ for the $c_{p}$ vs. $b_{b p}$ relationships at 470 and $526 \mathrm{~nm}$, respectively) and the fitted relationships could reproduce the observations with a bias of $-4 \%$ and $6 \%$ and a precision of $11 \%$ and $9 \%$ in the blue and green channels, respectively (bias and precision are defined as the median and $\sigma_{p}$ of the relative residuals.) Our observations were also found in general agreement with published bio-optical models (Fig. 5).

While both surface chlorophyll- $a$ and particle concentrations tracked $c_{p}$ and $b_{b p}$, the former displayed larger relative variations (up to 8-fold) than the latter (Fig. 4b). At

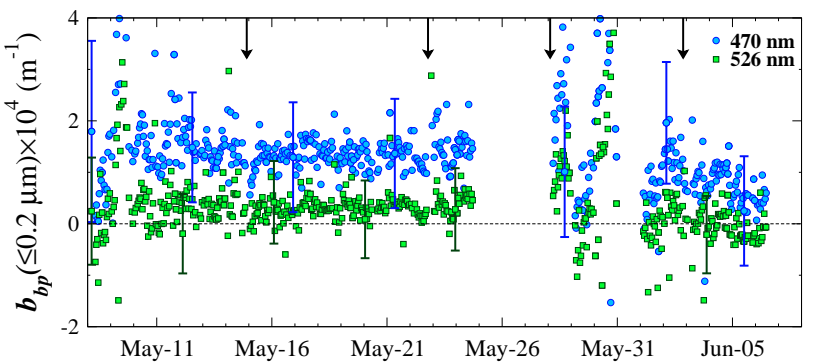

Fig. 7. $b_{b p}(<0.2 \mu \mathrm{m})$ data as a function of wavelength extrapolated from the hourly $0.2-\mu \mathrm{m}$ filtered $b_{b p}$ measurements (see text for details). Arrows indicate the times when the $0.2-\mu \mathrm{m}$ cartridge filters were changed.

$526 \mathrm{~nm}$, the $b_{b p}: c_{p}$ ratio exhibited a relatively constant median value along the cruise track $(0.0112 \pm 0.0013)$. On the other hand, the $b_{b p}$ :chl- $a$ ratio was more variable $(0.0066 \pm$ $0.0020 \mathrm{~m}^{2} \mathrm{~m} \mathrm{~g}^{-1}$ ) (Fig. 4c). Both these ratios displayed diel variations, which were absent form the bulk properties.

$b_{b p}$ was positively related to chlorophyll- $a$ concentration, and in good agreement with the model proposed by Morel and Maritorena (2001) and Huot et al. (2008) (Fig. 6a and b). On the other hand, existing models overestimated the observed $b_{p}$ values by about $15 \%$ (Fig. 6c and d).

The slopes of the power-law PSD fits were symmetrically distributed around a median value $\left( \pm \sigma_{p}\right)$ of $3.49 \pm 0.37$ Thus, the shape of particle size distributions was relatively constant in the sampled region for sizes varying between 2 and $8 \mu \mathrm{m}$.

\subsection{Backscattering from $0.2-\mu \mathrm{m}$ filtered samples}

Figure 7a shows that the hourly $b_{b p}(<0.2 \mu \mathrm{m})$ data were remarkably constant along the cruise track and accounted for an insignificant fraction of the bulk signal even though the $b_{b p}(<0.2 \mu \mathrm{m})$ values for the blue channel were systematically larger than the green ones. The times when $b_{b p}(<$ $0.2 \mu \mathrm{m}$ ) showed local maxima (9 May and 1 June) corresponded to local maxima in the bulk $b_{b p}$ values (compare with Fig. 4c). In those occasions the 10-min 0.2- $\mu \mathrm{m}$ filtration time may not have been long enough and, as a consequence, the $b_{b p}(<0.2 \mu \mathrm{m})$ extrapolated from the fits were inaccurate. Another explanation could be that there might have been residual bubbles in the sample water. Finally, the coefficients of determination for the linear relationships between $b_{b p}(<0.2 \mu \mathrm{m})$ and other variables such as chl- $a$, bulk $b_{b p}$, $c_{p}$, temperature and salinity were always smaller than 0.07 .

\subsection{Along track size-fractionated IOPs}

Particles smaller than $3 \mu \mathrm{m}$ contributed $53 \% \pm 7 \%$ and $51 \% \pm$ $7 \%$ of the bulk $b_{b p}$ measurements at 470 and $526 \mathrm{~nm}$, respectively, and $40 \% \pm 9 \%$ and $46 \% \pm 5 \%$ of the bulk $c_{p}$ at 526 and 

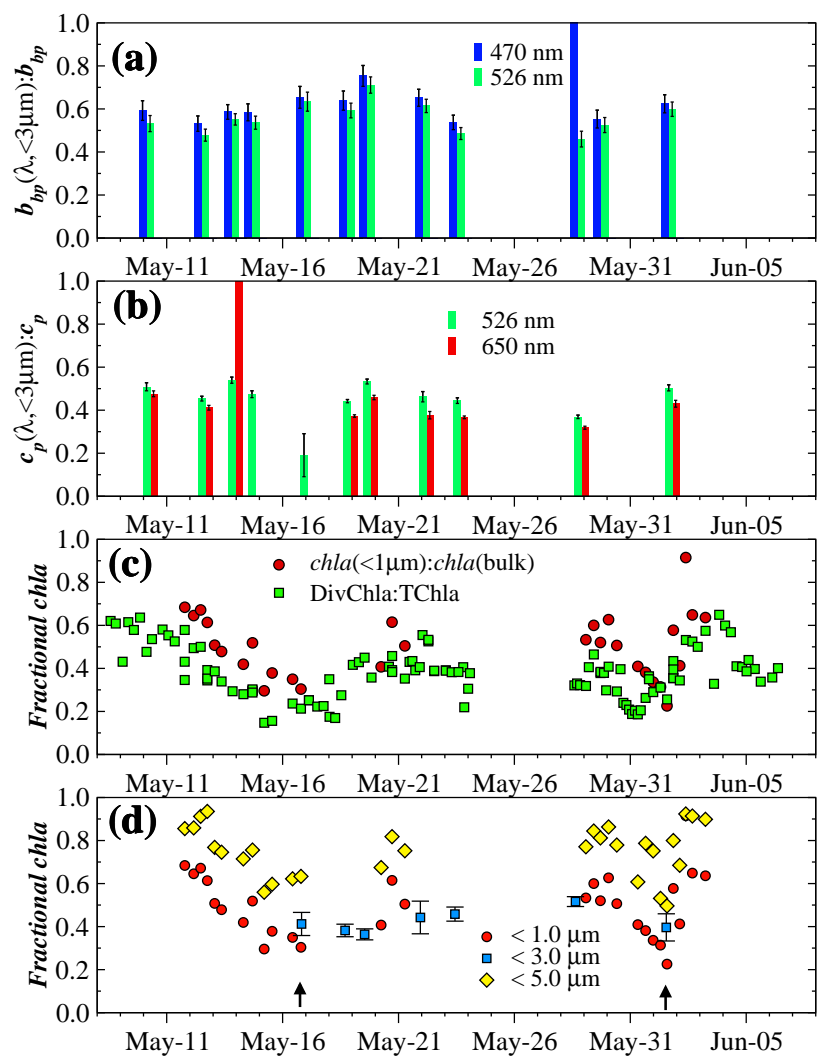

Fig. 8. Fractions of $b_{b p}$ and $c_{p}$ smaller than $3 \mu \mathrm{m}$, (a) and (b), respectively; error bars represent combined experimental uncertainties. (c) relationship between the fraction of chl- $a$ due to particles smaller than $1 \mu \mathrm{m}$ obtained from the size-fractionated chl- $a$ measurements, and the HPLC-derived fractional contribution of divinyl chl- $a$ to TChl- $a$. (d) fractional contributions to chl- $a$ from particles $<1$ and $<5 \mu \mathrm{m}$ (derived form the fractionated chl- $a$ measurements) and from particles $<3 \mu \mathrm{m}$ (derived from filtered $a_{p}$ measurements). Black arrows in (d) indicate the two concurrent AC-s and fractionated chl- $a$ measurements.

$650 \mathrm{~nm}$, respectively (Fig. 8a, b). The fraction of chl- $a$ originating from particles smaller than $1 \mu \mathrm{m}$ was generally higher than the ratio DivChl- $a$ :TChl- $a$ (Fig. $8 \mathrm{c}$ ) and accounted for $51 \% \pm 15 \%$ of the total chl- $a$. Panel (d) of Fig. 8 shows that, when concurrent data were available (unfortunately, only on two occasions), the fraction of chl- $a$ originating from particles $<3 \mu \mathrm{m}$ and derived from filtered AC-s measurements was between the chl- $a$ originating from particles $<1$ and $<5 \mu \mathrm{m}$.

An attempt was made to simulate the observed $c_{p}$ and $b_{b p}$, when along-track PSDs measurements were available. Briefly, the minimum particle diameter was set at $0.2 \mu \mathrm{m}$ and the imaginary part of the refractive index at 0.0005 , while the real part of the refractive index and the maximum particle diameter were allowed to vary (see Appendix A for detailed methods). Results of Mie calculations showed that two in- (a)

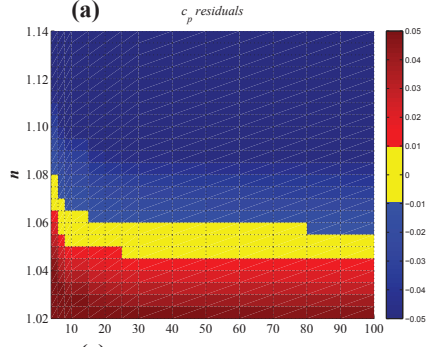

(c)

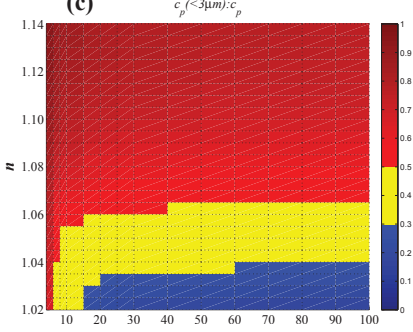

(e) optimum $\left(n, D_{\max }\right)$ for $c_{p}$

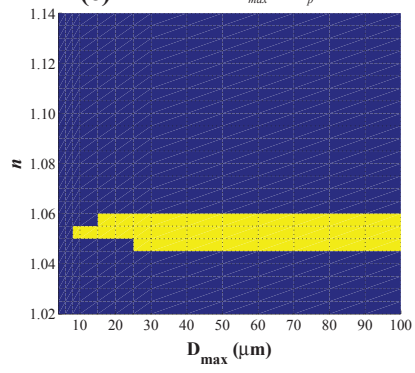

(b)

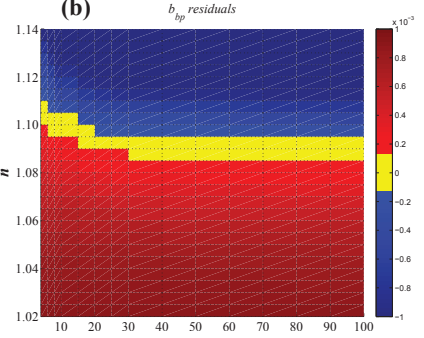

(d)

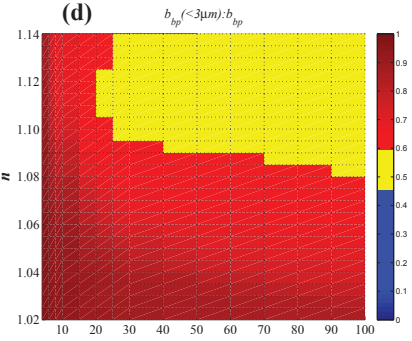

(f) $\operatorname{optimum}\left(n, D_{\text {max }}\right)$ for $b_{b p}$

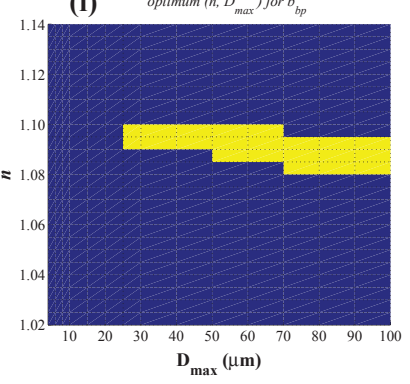

Fig. 9. Comparison of observed vs. simulated $c_{p}$ and $b_{b p}$ as a function of the real part of the refractive index $(n)$ and maximum diameter $\left(D_{\max }\right)$. The imaginary part of the refractive index was fixed at 0.0005 , the minimum diameter used in the simulations was $0.2 \mu \mathrm{m}$. Median residuals (observation - model, $\mathrm{m}^{-1}$ ) of $c_{p}$ from the C-star transmissometer (a) and of $b_{b p}$ (b). Median ratios of $c_{p}(<3 \mu \mathrm{m}): c_{p}$ (c) and $b_{b p}(<3 \mu \mathrm{m}): b_{b p}$ (in yellow the observed ranges) (d). Optimal sets (in yellow) of $n$ and $D_{\max }$ for $c_{p}$ (e) and $b_{b p}$ (f).

compatible particle populations characterized by different refractive indices were needed to simulate $c_{p}$ and $b_{b p}$ (Fig. 9). The population characterized by a lower real part of the refractive index $(\sim 1.055)$ allowed to successfully reproduce the observed $c_{p}$ (Fig. 9a, c), but contributed only about $40 \%$ of the bulk observed backscattering (compare Fig. 9e and b). On the other hand, the population with a higher real part of the refractive index $(\sim 1.090)$ replicated satisfyingly the observed $b_{b p}$ data (Fig. $9 \mathrm{~b}, \mathrm{~d}$ ), but also generated a $c_{p}$ that was in median $60 \%$ larger than the measured one (compare Fig. 9f and a).

\subsection{Fractionation experiments}

The first fractionation experiment took place at the equator $\left(0^{\circ}, 140^{\circ} \mathrm{W}\right)$ in relatively mesotrophic conditions (TChl$a=0.25 \mathrm{mg} \mathrm{m}^{-3}$, bulk $c_{p}(526)=0.14 \mathrm{~m}^{-1}$; Figs. 1 and $4 \mathrm{c}$ ). 

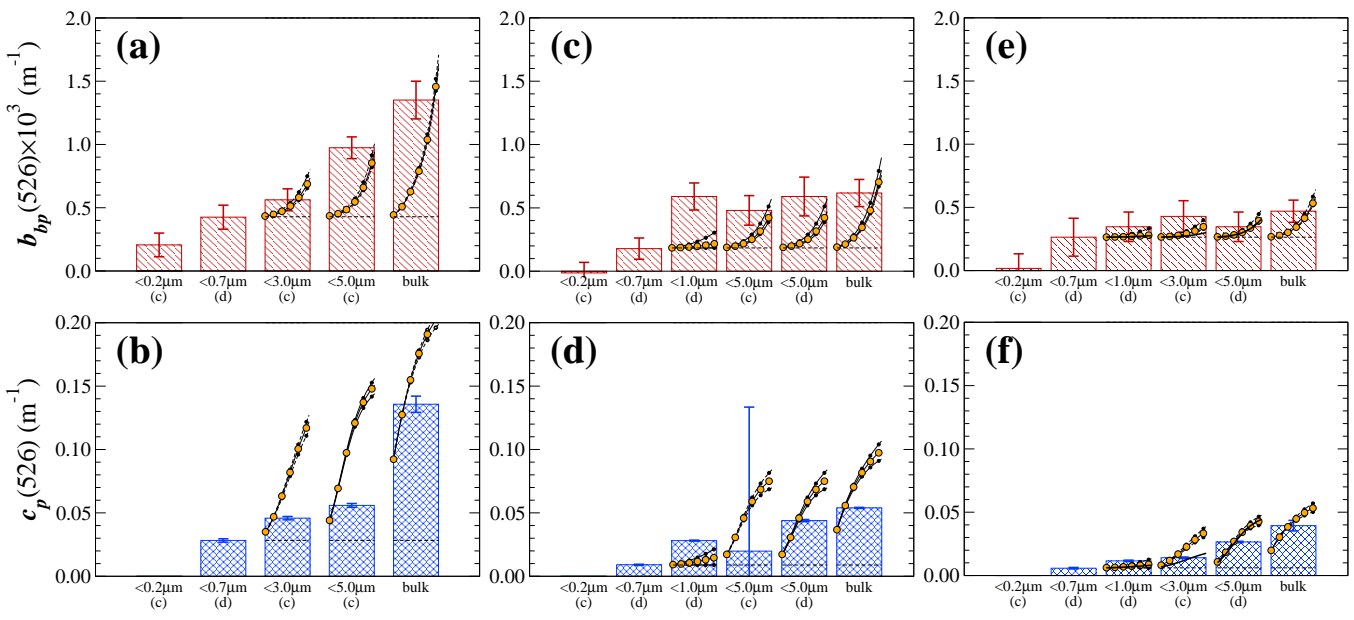

Fig. 10. Particle backscattering (top) and beam-attenuation (bottom) coefficients measured at $526 \mathrm{~nm}$ during the first (a, b), second (c, d), and third (e, f) fractionation experiments. Bars represent measured IOPs for the indicated size fractions, the rightmost bars represent the bulk measurements. Error bars represent combined experimental uncertainties. Lines with large symbols are results from Mie simulations for the size fractions larger than $0.7 \mu \mathrm{m}$ and smaller than the sizes reported below each bar (see Appendix A for details). Dashed lines with small symbols are results of the sensitivity analysis to the filtration efficiency of the $0.7 \mu \mathrm{m}$ filters. Horizontal dashed lines mark the $b_{b p}$ (a, $\mathrm{c}, \mathrm{e})$ and $c_{p}(\mathrm{~b}, \mathrm{~d}, \mathrm{f})$ values recorded for the size fraction $<0.7 \mu \mathrm{m}$. Modeled $b_{b p}$ and $c_{p}$ values for different refractive indices are presented (from left to right: $1.020,1.035,1.050,1.065,1.080$, and 1.095). The letters in parentheses below the bars indicate the type of filter used: $\mathrm{c}=$ cartridge, $\mathrm{d}=$ disk. Thick continuous lines in $(\mathrm{e}, \mathrm{f})$ represent simulations completed using the PSDs measured on each size-fractionated sample.

The differential particle distribution measured on bulk samples showed a peak centered around $1.5 \mu \mathrm{m}$ and superimposed on the power law shape and presented the largest total number of particles of the three experiments. The second and third experiments were completed in the more oligotrophic north Pacific gyre $\left(9^{\circ} \mathrm{N}, 140^{\circ} \mathrm{W}\right.$, and $15.4^{\circ} \mathrm{N}, 150.4^{\circ} \mathrm{W}$, respectively; TChl- $a=0.07$ and $0.04 \mathrm{mg} \mathrm{m}^{-3}$, bulk $c_{p}(526)=$ 0.054 and $0.039 \mathrm{~m}^{-1}$, respectively; Figs. 1 and $4 \mathrm{c}$ ) and presented smoother particle size distributions and significantly lower numbers of particles between 1.4 and $40 \mu \mathrm{m}$ (12529, 5202, and 2920 particles per $\mathrm{ml}$ for the 1st, 2nd, and 3rd experiments, respectively).

During the first fractionation experiment, approximately $68 \%$ and $80 \%$ of the bulk $b_{b p}$ and $c_{p}$ signals, respectively, were generated by particles greater than $0.7 \mu \mathrm{m}$ (Fig. 10a, b). Approximately $58 \%$ of the bulk $b_{b p}$ was generated by particles greater than $3 \mu \mathrm{m}$. In the more oligotrophic waters sampled during the 2nd and 3rd experiments, particles greater than $0.7 \mu \mathrm{m}$ contributed $71 \%$ and $43 \%$ of the bulk $b_{b p}$ respectively (Fig. 10c-f). This size fraction however, contributed about the same percentage of the bulk $c_{p}$ signal, i.e. $83 \%$ and $85 \%$, respectively (Fig. 10c-f).

Simulation results (see Appendix A) indicated that, in general, Mie theory required higher refractive indices to match $b_{b p}$ than $c_{p}$ although uncertainties in measured $b_{b p}$ are rather large in the third fractionation experiment (Fig. 10). A sensitivity analysis also showed that imperfections in the filtration efficiency of the $0.7 \mu \mathrm{m}$ filters used as baselines for the sim- ulations did not introduce significant uncertainties (dashed black lines in Fig. 10).

\section{Discussion}

\subsection{Bulk inherent optical properties}

In this study continuous measurements of bulk inherent optical properties and discrete biogeochemical parameters have been presented for surface waters of the Equatorial Pacific during May 2007. In addition to the bulk measurements, size-fractionated data on $b_{b p}, c_{p}, a_{p}$, and chl- $a$ were collected and analyzed. Other investigators have studied sizefractionated $c_{p}$ and $a_{p}$ in the oligotrophic Crater Lake (Boss et al., 2007), size-fractionated $b_{b p}$ measurements in productive coastal waters (Roesler and Boss, 2008), and sizefractionated $c_{p}$ in the Equatorial Pacific (Chung et al., 1996). Here, for the first time to the best of our knowledge, sizefractionated $b_{b p}$ data are presented for open-ocean waters and a comparison of different size-fractionated inherent optical properties is undertaken.

Two technical and methodological innovations were critical for the collection of the data set presented in this study. First, highly accurate calibration-independent flowthrough measurements of particulate beam-attenuation and absorption coefficients were achieved by applying a correction based on temporally adjacent $0.2-\mu \mathrm{m}$ filtered measurements. Second, a novel custom-made flow-through chamber 
allowed continuous surface particle backscattering measurements. A total of more than $35000 \mathrm{~min}$-averaged data points of concurrent $b_{b p}$ and $c_{p}$ were retrieved during the cruise with this system.

The accuracy of the measured inherent optical properties was determined through favorable comparison between $c_{p}$ measured on the flow-through system and on the CTD, between measured and modeled $R_{r s}$ values (see Method section), as well as through closure of $c_{p}$ with Mie theory (Figs. 9a and b and 10b, $d$ and $\mathrm{f}$ ). In addition, median $b_{b p}: b_{p}$ ratios $\left( \pm \sigma_{p}\right)$ were consistent with the ranges reported for other oligotrophic waters (i.e., 0.0119 \pm 0.0016 and $0.0105 \pm 0.0013$, at 470 and $526 \mathrm{~nm}$, respectively; Whitmire et al., 2007; Stramski et al., 2008, but see Twardowski et al., 2007).

Particle backscattering and beam-attenuation (or scattering) coefficients were tightly correlated (Fig. 5) and in agreement with other studies and published bio-optical models (Loisel and Morel, 1998; Morel and Maritorena, 2001; Huot et al., 2008). Despite the absence from our data of previously observed diel cycles in $c_{p}$ (e.g., Siegel et al., 1989), both the $b_{b p}: c_{p}$ and $b_{b p}:$ chl- $a$ ratios showed such cycles (compare Fig. 4a and c). It may be argued that these cycles arise because $b_{b p}$ and $c_{p}$ are sensitive to different particle populations (e.g., small vs. large) whose temporal dynamics are out of phase. However, an alternative explanation may be that these variations resulted from differences in the sensitivities of $b_{b p}$ and $c_{p}$ to morphological and/or compositional (e.g., Stramski and Reynolds, 1993) changes in the same average particle population. Alternatively, these cycles could arise because of biases in $c_{p}$ due to the finite acceptance angle of the transmissometer (Boss et al., 2009). Finally, variations in $b_{b p}: c_{p}$ were limited and did not compromise the overall covariation between $b_{b p}$ and $c_{p}$.

Taken together our findings suggest that a common particle pool contributes, at least in part, to both $b_{b p}$ and $c_{p}$. In agreement with this conclusion, PSD exponents derived by fitting Coulter counter data between 2 and $8 \mu \mathrm{m}$ varied by about $10 \%$ along the cruise and a significant fraction of $b_{b p}$ originated from particles in the phytoplankton size range (see below).

\subsection{Phytoplankton carbon from scattering coefficients}

Relatively conserved first order relationships between particulate organic carbon (POC) and $c_{p}$ have been repeatedly observed in field data (e.g., Claustre et al., 1999; Stramski et al., 1999; Behrenfeld and Boss, 2006; Gardner et al., 2006; Stramski et al., 2008). One way to interpret the observed covariation of POC with $c_{p}$ is that the relationship between the carbon-specific scattering cross-section of the "average particle" is, to first order, constant. However, this constancy is not expected a-priori, because the particles contributing to POC and the scattering coefficient vary over a large range of sizes and should have different compositions (e.g., Stramski et al., 2008).

On the other hand, numerous laboratory studies have shown that the phytoplankton carbon-specific scattering cross-section is constrained between 2 and $4 \mathrm{~m}^{2} \mathrm{gC}^{-1}$ for cells belonging to different groups (from cyanobacteria to diatoms) and grown under different conditions (Stramski and Morel, 1990; Stramski and Reynolds, 1993; DuRand et al., 2002). Thus, based on the laboratory data currently available and on the particulate vs. phytoplankton scattering proportionality (see our argument in the introduction), it should be less surprising that the $b_{p}$ vs. phytoplankton-carbon relationship exists than a $b_{p}$ vs. POC relationship.

Yet, the relationships between POC and $b_{p}$ observed throughout the world oceans remain and the derived POCspecific scattering cross sections $\left(1.5-3.8 \mathrm{~m}^{2} \mathrm{gPOC}^{-1}\right)$ are in agreement to those measured in the laboratory for phytoplankton carbon, despite differences in geographic areas, protocols, and instrumentation (e.g., Claustre et al., 1999; Stramski et al., 1999; Behrenfeld and Boss, 2006; Gardner et al., 2006; Stramski et al., 2008). Our explanation for these findings is that phytoplankton may contribute a significant fraction of POC and $b_{p}$, and/or that the other particles affecting POC and $b_{p}$ covary with phytoplankton and, possibly, have similar carbon-specific scattering cross-sections. Unfortunately, the direct measurement of phytoplankton carbon biomass is rare relative to POC measurements, so a similar analysis has not been conducted. Nevertheless, substantial indirect evidence for a $b_{p}$ (or $\left.b_{b p}\right)$ vs. phytoplankton-carbon relationship does exists (Behrenfeld and Boss, 2003; Behrenfeld et al., 2005; Siegel et al., 2005; Behrenfeld and Boss, 2006; Huot et al., 2007; Westberry et al., 2008).

Finally, the variability in the carbon-specific scattering cross-section of phytoplankton will introduce uncertainties in the conversion of $b_{p}$ to phytoplankton carbon. However, these uncertainties should be compared to those of phytoplankton carbon biomass derived from chlorophyll- $a$. It is indeed well documented that the ratio of chlorophyll- $a$ to phytoplankton carbon can vary by almost two orders of magnitude (e.g., MacIntyre et al., 2002; Behrenfeld et al., 2005). Thus, we believe that scattering measurements represent a reliable alternative to chl- $a$ for estimating phytoplankton carbon biomass in the open ocean.

\section{$4.3 b_{b p}(<0.2 \mu \mathrm{m})$}

An important observation recorded during this study was the relatively constant and statistically insignificant backscattering of $0.2 \mu \mathrm{m}$-filtered seawater, $b_{b p}(<0.2 \mu \mathrm{m})$ (Fig. 7). There were no evident changes in $b_{b p}(<0.2 \mu \mathrm{m})$ when the $0.2 \mu \mathrm{m}$ cartridge filters were replaced during the cruise (black arrows in Fig. 7). Thus, filter clogging and retention of particles $<0.2 \mu \mathrm{m}$ did not appear significant. This finding, if independently confirmed, is important because it challenges previous theoretical predictions that attributed about $50 \%$ of $b_{b p}$ 
to particles smaller than $0.2 \mu \mathrm{m}$ (when the PSD exponent is -4, Fig. 4b in Stramski and Kiefer, 1991).

\subsection{Size-fractionated inherent optical properties}

The along-track $3-\mu \mathrm{m}$ filtrations, as well as the fractionation experiments, demonstrated that particles larger than $3 \mu \mathrm{m}$ directly contributed about $60 \%$ and $50 \%$ of the bulk particulate and backscattering coefficients, respectively, in the mesotrophic regions sampled (Figs. 8a and 10a). Fractional $c_{p}$ data for particles $<3 \mu \mathrm{m}$ were found in agreement with the range of fractional $c_{p}$ for particles $<8 \mu \mathrm{m}(41-89 \%)$ reported by Chung et al. (1996).

The $50 \%$ contribution from particles $>3 \mu \mathrm{m}$ to $b_{b p}$ in the mesotrophic regions is significant, because it establishes a direct link between the biomass of particles in the phytoplankton-size range and a remotely-sensed parameter that is believed to be mostly influenced by sub-micron detrital particles (Stramski and Kiefer, 1991; Morel and Ahn, 1991). In the most oligotrophic part of our transect $b_{b p}$ was dominated by sub-micron particles $(0.2-1.0 \mu \mathrm{m}$, Fig. 10e and f). However, more data are needed to verify this interesting finding.

\subsection{Size-fractionation by filtration}

The fractionated backscattering and beam-attenuation coefficients reported in this study were determined by filtration of seawater samples. Filtration is a technique widely used in oceanographic research to partition the continuous size distribution that naturally occurs in water samples. For example, Ciotti et al. (2002) used data on size-fractionated chlorophyll concentration to parameterize a size-dependent model of phytoplankton absorption. Other investigators have used size-fractionation to relate the bloom of specific phytoplankton groups to nanomolar increases in nitrate in the Sargasso Sea (Glover et al., 1988) or to follow the seasonal cycle of phytoplankton blooms (Clarke and Leakey, 1996).

Despite its widespread use, size-fractionation based on filtration has its disadvantages. Filters can retain a significant fraction of particles smaller than the declared pore size and the amount of this unwanted fraction depends on the particle stickiness coefficient and on the filter type (Sheldon, 1972; Logan, 1993; Logan et al., 1994; Chavez et al., 1995; Knefelkamp et al., 2007). The main reason for the mismatch between nominal pore sizes and actual retained sizes appears to be filter clogging and the inability to accurately define the pore size of filters (e.g., Droppo, 2000). Filter clogging was minimized during our $0.2-$ and $3-\mu \mathrm{m}$ filtrations by means of cartridge filters with large surface areas $\left(0.64 \mathrm{~m}^{2}\right)$ and by replacing filters frequently. In addition, the filtration of samples in-situ should have minimized particle aggregation and precipitation. Clogging and statistical fluctuations of our results were further decreased during our large-volume size- fractionation experiments by filtering small amounts of sample through each filter.

The following considerations are presented as evidence that the results obtained from the fractionation experiments were minimally affected by filter clogging and, thus provide a reasonable representation of size-fractionated IOPs. First, the validity of the fractionated-chl- $a$ measurements is established by noting that a large fraction (range $20-70 \%$, median $51 \%$ ) of the bulk chl- $a$ was retained on the $0.7 \mu \mathrm{m}$ filter, but not on the $1.0 \mu \mathrm{m}$ filter (Fig. 8c, red circles), indicating that the $1.0 \mu \mathrm{m}$ filters did not retain considerable amounts of particles smaller than their pore size. Moreover, the $<1 \mu \mathrm{m}$ size fraction typically contained more chl- $a$ than the DivChl$a$ :TChl- $a$ values derived from the HPLC analysis of $0.7 \mu \mathrm{m}$ filtered samples (Fig. 8c). Since DivChl- $a$ is a pigment typical of the genus Prochlorococcus with typical average diameter of $0.5-0.7 \mu \mathrm{m}$ (e.g. Grob et al., 2007), this observation independently verifies that the $1-\mu \mathrm{m}$ Nuclepore filters were not trapping a significant number of particles smaller than their pore size. Similarly, samples processed through disk filters during the fractionation experiments should not have been significantly affected by filter clogging, to the extent that the larger seawater volumes filtered during the fractionation experiments did not cause significant obstruction of filter pores. This hypothesis was partially validated by the only two fractional chl- $a$ values derived from the alongcruise 3- $\mu \mathrm{m}$ filtered $a_{p}$ measurements and concurrent to the size-fractionated chl- $a$ (Fig. 8d). Finally, effective partitioning of the size distribution is also evidenced by the closure (in terms of refractive index range) achieved between Mie simulations and measurements of the fractionated $c_{p}$ (Figs. 9e and $10 \mathrm{~b}, \mathrm{~d}, \mathrm{f}$ ). Thus, although not perfect, measurements of size-fractionated water samples can provide important insights on the relative contributions of different particles to the bulk inherent optical properties. Future investigations should stress collection of comprehensive ancillary measurements, including particle size distributions, for each size fraction.

\subsection{Comparison of observations with theory}

The notion that light in the open ocean is mostly backscattered by sub-micron detrital particles is founded on theoretical modeling of light scattering by homogeneous spheres (Stramski and Kiefer, 1991; Morel and Ahn, 1991). These theoretical predictions force one to conclude that phytoplankton cells have a negligible contribution to $b_{b p}$ and have been verified by some authors in the laboratory (Morel and Ahn, 1991; Ahn et al., 1992). It is noteworthy, however, that these experiments were all based on the same technique and hypotheses: conversion of the measured volume scattering function at a narrow angular range into $b_{b p}$. On the other hand, many independent experimental (Zielinski et al., 1986, 1987; Quinby-Hunt et al., 1989; Volten et al., 1998; Stramski and Piskozub, 2003; Vaillancourt et al., 2004) and theoretical (Meyer, 1979; Kitchen and Zaneveld, 1992; Quirantes 


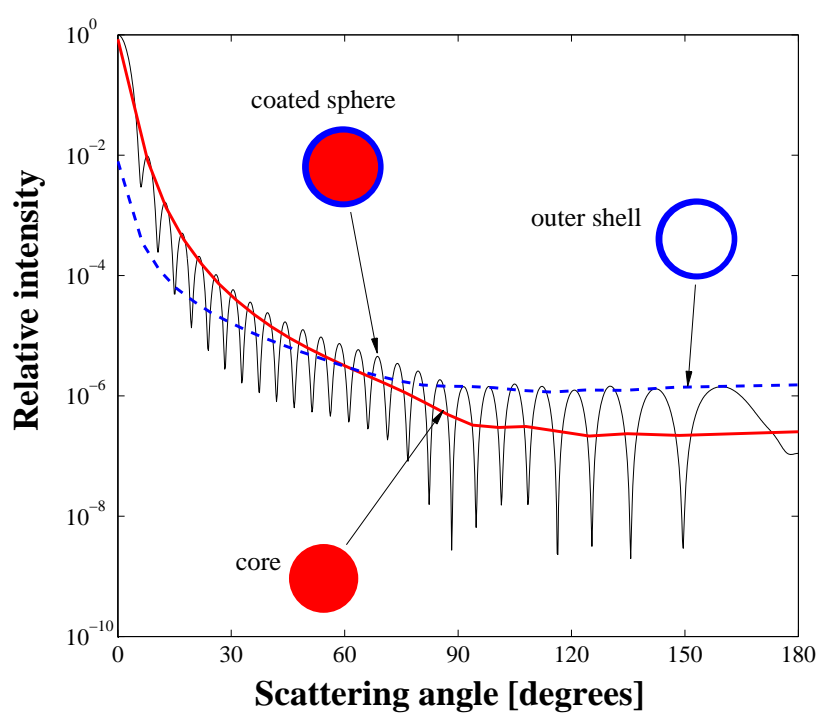

Fig. 11. Example of how the scattered intensity (normalized at an angle of 0 degrees) of a coated sphere (thin black line) can be approximated by the sum of the scattered intensity of its homogeneous core (thick red line) that contributes most of the forward scattering, and by the scattered intensity generated by its outer shell (dashed blue line, not to scale in the figure) that generates most of the backscattering $\left(\lambda_{\mathrm{vac}}=520 \mathrm{~nm}\right)$. Scattered intensities were multiplied by the corresponding scattering cross-sections relative to the scattering cross-section of the coated-sphere. The diameter of the homogeneous core was $4.99 \mu \mathrm{m}$ and its refractive index relative to seawater was $1.02+0 i$. The shell thickness was $0.01 \mu \mathrm{m}$ and its relative refractive index was $1.15+0 i$. Only the envelopes of the maxima structures for the core and shell relative scattered intensities are presented for clarity. The backscattering ratio of the coated sphere was 5 times that of its core. Modified after Meyer (1979).

and Bernard, 2004, 2006; Clavano et al., 2007) investigations have provided strong evidence that the homogeneous spherical model is inappropriate for modeling the back-scattering coefficient of phytoplankton.

Our results are in agreement with the latter studies: our Mie simulations could not simultaneously reproduce the measured $c_{p}$ and $b_{b p}$ (Figs. 9 and 10). This is likely because the shape of the volume scattering function (but not the total scattering) is sensitive to the internal structure and non-sphericity of natural particles (Meyer, 1979; Kitchen and Zaneveld, 1992; Quirantes and Bernard, 2004; Clavano et al., 2007). In other words, the relative amount of light scattered in the backward direction is higher for a microorganism that contains internal organelles and membranes than for a homogeneous sphere with the same average refractive index.

Particularly insightful with this respect is the study by Meyer (1979), who demonstrated that the scattering intensity of a coated sphere can be approximated by the sum of the scattering intensities due to two simpler particles (Fig. 11).
The first of these particles accounts for most of the forward part of the scattering intensity and is the homogeneous core of the coated sphere. The other particle contributes most of the backscattering and is the hollow-sphere that constitutes the shell of the coated sphere. Thus, the scattering intensity of a complex coated sphere can be approximately predicted by employing two different and simpler particles that separately contribute most of the forward and most of the backward scattering, respectively. This theoretical finding could likely be the reason for why two (or more) particle populations are needed when trying to reproduce volume scattering functions measured in-situ using the homogeneous spherical model (Figs. 9 and 10; see also Brown and Gordon, 1974; Kitchen and Zaneveld, 1992). Moreover, oceanic microorganisms modeled as coated spheres can contribute up to one order of magnitude more backscattering than when modeled as homogeneous spheres (Kitchen and Zaneveld, 1992; Quirantes and Bernard, 2006; Bernard et al., 2009). Therefore, the coated spherical model could help resolving the "backscattering enigma" (Stramski et al., 2004) and, at the same time, explain the strong correlation we found between $c_{p}$ and $b_{b p}$ (Fig. 5).

It is also noteworthy that the models proposed by Twardowski et al. (2001) and Mobley et al. (2002) predict that the average particle in our study should have a value of the real refractive index close to 1.1 , when using as inputs for the model the median $b_{b p}: b_{p}$ ratio at $526 \mathrm{~nm}$ and the median slope of the PSD derived in this study ( 0.010 and -3.5 , respectively). Thus, these models predict that a single particle population simultaneously contribute to $c_{p}$ and $b_{b p}$. This prediction disagrees with our results that indicate that Mie theory was unable to simultaneously reproduce the measured $c_{p}$ and $b_{b p}$ using a single population of particles (Figs. 9 and 10). The likely explanation for this disagreement is that both the above models assume that very small and large particles contribute significantly to the measured optical properties $(0.006-73 \mu \mathrm{m}$, in Twardowski et al., 2001 and $0-\infty \mu \mathrm{m}$ for the Fournier-Forand phase functions used by Mobley et al., 2002). Our negligible $b_{b p}(<0.2 \mu \mathrm{m})$ values are however at odds with this assumption and the cumulative seawater sample over which our data are binned is too small to measure particles larger than about 40-100 $\mu \mathrm{m}$. Furthermore, the finite acceptance angles of our transmissometers also act as filters for the signals generated by large particles (Boss et al., 2009). Instead, very large particles have been shown to be important in Mie theory simulations when the PSD exponent is -3.5 and when the finite acceptance angle is not accounted for. For example, Stramski and Kiefer (1991) needed to increase their maximum diameter to $1000 \mu \mathrm{m}$ to achieve a saturation in their cumulative scattering contribution when the PSD exponent was set at -3.5 . In addition, the refractive index of 1.1 appears to be rather large for open ocean waters as the surface Equatorial Pacific notoriously deficient in atmospheric dust deposition (Mahowald et al., 1999) and thus likely dominated by organic particles. We recognize that a 
value of $n=1.1$ is on the theoretical upper range for phytoplankton (1.06 \pm 0.04 , Aas, 1996), but it is also significantly higher than values expected for "soft" organic particles typical of open ocean waters (1.02-1.05, Zaneveld and Pak, 1973; Carder et al., 1972). Thus, the $n=1.1$ derived from our median backscattering ratio and median PSD exponent using the models by Twardowski et al. (2001) and Mobley et al. (2002) could be overestimating the actual average $n$.

Finally, so far we have been implicitly assuming that measured $c_{p}$ values can be accurately reproduced by using homogeneous spheres as models of phytoplankton cells. This assumption is based on theoretical findings showing little sensitivity of the absorption and total scattering coefficients to particle inhomogeneities and shape (e.g., Meyer, 1979; Clavano et al., 2007). Admittedly, a non-spherical population of particles can produce in certain cases important deviations from the optical properties of volume-equivalent spheres (Clavano et al., 2007). However, such deviations are expected to be constrained to about $20-30 \%$ for aspect ratios ranging from 0.5 to 2 . Only at extreme aspect ratios and for non-spherical particles with $\mathrm{ESD}>10 \mu \mathrm{m}$, the deviations become very significant (Clavano et al., 2007). Since nonsphericity is an attribute typical of large cells, and since those large cells are usually rare in the surface waters of the Equatorial Pacific and likely undersampled by our instrumentation (see above), we believe that our assumption is valid.

\subsection{Final remarks}

A direct influence of particles in the phytoplankton size range on $b_{b p}$ and the conserved shape of the particle size distribution create a close correspondence between $b_{b p}$ and $c_{p}$ variability (Fig. 5). These findings add to previous studies that have 1) demonstrated in the laboratory that the carbonspecific scattering cross-section of different phytoplankton groups grown under different conditions is rather constrained (Stramski and Morel, 1990; Stramski and Reynolds, 1993; DuRand et al., 2002); 2) suggested that $c_{p}$ can track phytoplankton biomass (Durand and Olson, 1996; Chung et al., 1996, 1998; Green et al., 2003; Oubelkheir et al., 2005); 3 ) shown that chl- $a: c_{p}$ ratios are closely correlated to variations in phytoplankton physiological parameters in the field (Behrenfeld and Boss, 2003); 4) demonstrated that the ratio of chl- $a$ to a function of $b_{b p}$ retrieved from ocean color data tracks physiological trends expected from laboratory experiments over vast oceanic regions (Behrenfeld et al., 2005); and 5) shown that the seasonal cycles of satellite-based chl$a: b_{b p}$ follow closely, in the oligotrophic ocean, those of the in-situ cellular fluorescence of Prochlorococcus (Westberry et al., 2008). Together, these different lines of evidence add support to the hypothesis that $b_{b p}$ can provide an alternative to chl- $a$ for monitoring open-ocean phytoplankton biomass from space (Behrenfeld et al., 2005; Westberry et al., 2008). It is additionally noteworthy that chlorophyll- $a$ concentrations during our Equatorial Pacific study spanned a range
( 0.05 to $0.4 \mathrm{mg} \mathrm{m}^{-3}$ ) representative of about $80 \%$ of the open ocean (based on satellite chl- $a$ retrievals). Accordingly, our results are likely relevant to many open-ocean regions, as has already been established for the South Pacific (Huot et al., 2008). Further verification is nevertheless desirable.

\section{Conclusions}

A field data set of bulk and size-fractionated measurements of inherent optical properties was presented and analyzed for the surface waters of the Equatorial Pacific during May 2007. These are the key findings and implications:

- $b_{b p}$ and $c_{p}$ were highly correlated, suggesting that, when considered with previous findings that bulk $c_{p}$ may be used effectively to track phytoplankton biomass, either particle scattering property should be equally valued as a remote-sensing proxy for phytoplankton biomass in open-ocean waters.

- $b_{b p}$ measurements of $0.2-\mu$ m filtered seawater were relatively constant across the sampled region and contributed negligibly to the bulk $b_{b p}$.

- Particles larger than $3 \mu \mathrm{m}$ contributed in median $50 \%$ of $b_{b p}$.

- Mie theory was unable to simultaneously reproduce the observed $c_{p}$ and $b_{b p}$ by means of a single population of particles.

\section{Appendix A}

\section{Comparison of observed vs. simulated $c_{p}$, and $b_{b p}$}

\section{A1 Along-track measurements}

Simulations were completed to assess the ability of Mie theory to reproduce the measured $c_{p}$ (from the C-star transmissometer) and $b_{b p}$ values. The input parameters for these simulations were the size distributions, minimum and maximum diameters, and complex refractive index of particles. The fitted PSD exponents were used to extrapolate measured PSDs to a minimum diameter of $0.2 \mu \mathrm{m}$ and to a maximum diameter $\left(D_{\max }\right)$ of $100 \mu \mathrm{m}$. The value of the minimum diameter was based on the negligible $b_{b p}(<0.2 \mu \mathrm{m})$ that was measured (Fig. 7) and on the use of $0.2 \mu \mathrm{m}$-filtered seawater for referencing $c_{p}$. The $D_{\max }$ was set as a conservative estimate of the maximum size of particles influencing our measurements based on the instantaneous volume sampled by the C-star transmissometer and by the BB3, as well as on the flow-rate, and on the effect of the finite acceptance angle of the transmissometer that acts as a filter for the large sized particles (Boss et al., 2009). This effect was also taken into account in the simulations. 
Simulations were then run for each PSD measured alongtrack for which coincident $c_{p}$ and $b_{b p}$ (at $526 \mathrm{~nm}$ ) were available (45 and 30 stations, respectively). $n$ was varied between 1.02 and 1.20 and $D_{\max }$ between 4 and $100 \mu \mathrm{m}$. The imaginary part of the refractive index was set at a nominal value of 0.0005 because particulate absorption is typically low at the wavelength selected for the simulations $(526 \mathrm{~nm})$. Then for each set of $n$ and $D_{\max }$ the median differences between the measured bulk $c_{p}$ and $b_{b p}$ and the corresponding simulated values were computed (Fig. 9a, b). To further constrain these results, the simulated ratios $c_{p}(<3 \mu \mathrm{m}): c_{p}$ and $b_{b p}(<3 \mu \mathrm{m}): b_{b p}$ were also computed for each set of $n$ and $D_{\max }$ and compared to the range measured for the corresponding along-track measurements (Fig. 9c, d). Finally, an optimal set of parameters for simulating $c_{p}$ was computed by identifying all sets of $n$ and $D_{\max }$ for which the median $c_{p}$ residuals were between $\pm 0.001 \mathrm{~m}^{-1}$ and the simulated $c_{p}(<3 \mu \mathrm{m}): c_{p}$ was between 0.3 and 0.5 . Similarly, an optimal set of parameters for simulating $b_{b p}$ was computed by identifying all sets of $n$ and $D_{\max }$ for which the median $b_{b p}$ residuals were between $\pm 0.0002 \mathrm{~m}^{-1}$ and the $b_{b p}(<3 \mu \mathrm{m}): b_{b p}$ was between 0.44 and 0.60 (Fig. 9e, f). The core routine for the simulations was based on Bohren and Huffman (1983).

Results show that the optimal set of $n$ and $D_{\max }$ for $c_{p}$ was located around $n=1.055 \pm 0.005$ and for $D_{\max }>20 \mathrm{um}$. On the other hand, for the $b_{b p}$ comparison the optimal range of $n$ was $n=1.080-1.095$ and the optimal $D_{\max }>25 \mu \mathrm{m}$ and covaried slightly with $n$ (Fig. 9e and f).

A sensitivity analysis was carried out to study the importance of the value chosen for the imaginary part of the refractive index $\left(n^{\prime}\right)$. All the above simulations were repeated for $n^{\prime}$ values of 0.0010 and 0.0000 . The optimal $n$ and $D_{\max }$ ranges did not vary considerably. The only difference was that when $n^{\prime}=0.0010$ there was no optimal set of $n$ and $D_{\max }$ for $b_{b p}$ within the range of parameters studied. In conclusion, the main result of these simulations was unaffected by the value of $n^{\prime}$ : with the imposed constraint on the minimum diameter, it was not possible to model simultaneously the measured $c_{p}$ and $b_{b p}$ values by using only one refractive index.

\section{A1.1 Fractionation experiments}

Simulations were also carried out to test the ability of Mie theory to reproduce the $c_{p}$ (from the C-star transmissometer) and $b_{b p}$ (at $526 \mathrm{~nm}$ ) measured during the three fractionation experiments. Particle size distributions (PSDs) of bulk samples were truncated in correspondence of the nominal pore sizes of the filters and used as input for the simulations. Measured PSDs were extrapolated from 1.4 to $0.3 \mu \mathrm{m}$ and from 8 to $100 \mu \mathrm{m}$ using the slope fitted between 2 and $8 \mu \mathrm{m}$. A peak around $1.5 \mu \mathrm{m}$ was fitted using a Gaussian model and added to the power-law distribution adopted for the extrapolation to lower sizes. To reduce uncertainties due to the extrapolation of the PSD to lower sizes, $c_{p}$ and $b_{b p}$ for the size

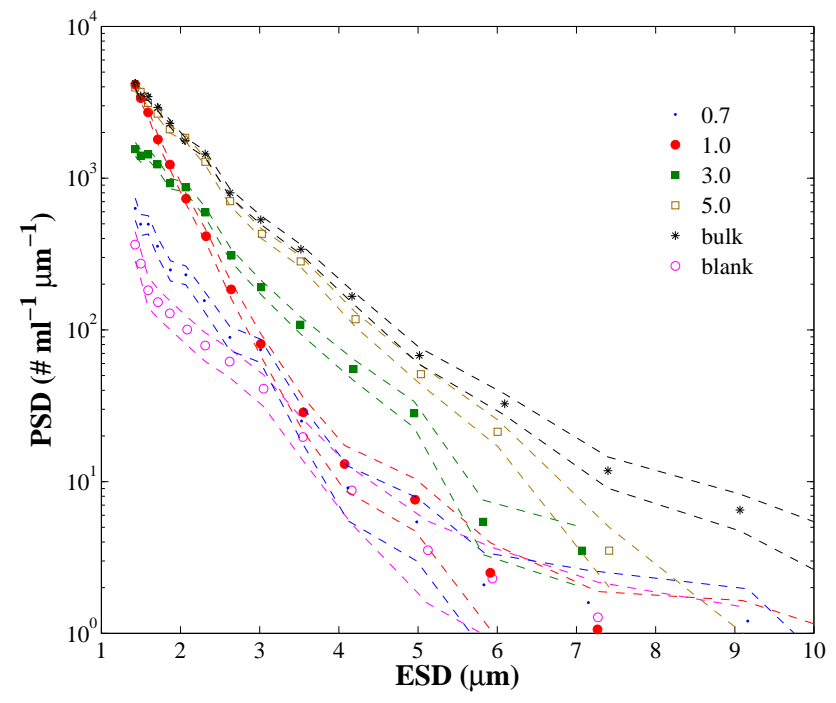

Fig. A1. Particle size distribution measurements aggregated over large bins for the size-fractionated samples collected during the third fractionation experiment. Dashed lines represent standard deviations.

fractions smaller than $0.7 \mu \mathrm{m}$ were assumed as known (from our measurements) and only the $c_{p}$ and $b_{b p}$ generated by size fractions larger than $0.7 \mu \mathrm{m}$ were modeled. The sensitivity of our results to this hypothesis was investigated by repeating the simulations assuming that the $0.7 \mu \mathrm{m}$ filter had instead trapped particles $>0.3$ and $>1 \mu \mathrm{m}$. $n$ was varied between 1.02 and 1.10 and $D_{\max }$ was set to $100 \mu \mathrm{m}$. The imaginary part of the refractive index was again set equal to 0.0005 .

\section{A1.2 Mie simulations with observed size-fractionated PSDs for the 3rd fractionation experiment}

The Mie simulations carried out for the three fractionation experiments were based on PSDs of bulk samples that were set to zero above the diameters corresponding to the nominal pore sizes of the filtered samples. This approach was taken because PSD measurements were not collected on the sizefractionated samples during the 1 st and 2 nd experiments. However, a limited set of PSDs were measured on the sizefractionated samples collected during the 3rd fractionation experiment.

Figure A1 presents the PSDs measured on the sizefractionated samples collected during the 3rd experiment and aggregated over larger bins. As expected, the PSD measurement of the $0.7-\mu \mathrm{m}$ filtered sample was only slightly larger than the blank (0.2- $\mu \mathrm{m}$ filtered seawater) at the smallest sizes. Similarly, the PSD of the 5- $\mu$ m filtered sample was only slightly smaller that the bulk sample for ESD smaller than $5 \mu \mathrm{m}$ and, as expected, decreased with respect to the bulk at larger ESDs. 
On the other hand, the $1-\mu \mathrm{m}$ and the $3-\mu \mathrm{m}$ filtered samples presented some problems. The PSD of the 1- $\mu$ m filtered sample had, as expected, values similar to those measured on the bulk sample at bin sizes of about $1.4 \mu \mathrm{m}$, but showed that some particles with ESD up to $2.5 \mu \mathrm{m}$ had passed through the filter (Fig. A1, compare filled red circles with black stars). This phenomenon may be explained by imperfect filter pores (e.g., two pores in contact with each other), by large soft particles that squeezed through the filter pores or disaggregated as they passed through the filter and re-aggregated afterwards, and/or by an incorrect nominal pore size of the filter. On the other hand, the PSD of the 3- $\mu$ m filtered sample retained a significant fraction of particles smaller than the nominal pore size.

Mie simulations were repeated using the PSDs measured on the size-fractionated samples and extrapolated to $0.3 \mu \mathrm{m}$. The PSD measured for the size fraction smaller $<1 \mu \mathrm{m}$ was much steeper than the observed bulk PSD. Thus, to avoid biasing the simulation, this PSD was extrapolated to $0.7 \mu \mathrm{m}$ by employing the slope of the bulk PSD.

Results for the 1- and 5- $\mu \mathrm{m}$ size fractions were consistent with those obtained using the truncated bulk PSDs (compare thick black lines with large circles in Fig. 10e, f). However, the new $b_{b p}$ and $c_{p}$ values simulated for the 3- $\mu \mathrm{m}$ size fraction were lower than those obtained from the truncated bulk PSD.

In conclusion, the PSD data measured on the sizefractionated samples during the 3rd fractionation experiment were in general agreement with the measured sizefractionated IOPs, exception made for the PSD collected for $3-\mu \mathrm{m}$ size fraction.

\section{Appendix B}

\section{$\chi_{p}$ of coated spheres}

One aspect of our analysis that may appear a contradiction to our overall conclusions is that the $\chi_{p}$ factor at $117^{\circ}$ adopted in this study was predicted by Mie theory and found to be in agreement with experimentally determined $\chi_{p}$ values (e.g., Boss and Pegau, 2001; Berthon et al., 2007). Recognition of this detail might incorrectly suggest that Mie theory is indeed able to accurately predict the $b_{b p}$ of oceanic microorganisms. However, this contradiction is resolved by considering that the use of the homogeneous or the coated cell models causes large differences in the simulated $b_{b p}: b_{p}$ ratio, but has only a minor impact on the $b_{b p}: \beta_{p}\left(117^{\circ}\right)$ ratio (i.e., $\left.\chi_{p}\right)$. To test this hypothesis we conducted a preliminary investigation where a coated spherical model (based on algorithms by Bohren and Huffman, 1983) was used to simulate the volume scattering functions of particles distributed between 0.4 and $100 \mu \mathrm{m}$ according to a power law with exponents between -3 and -4 . Particle sizes were determined by the radius of the core plus the thickness of the shell. We assumed that the shell thickness can either have a constant value of $75 \mathrm{~nm}$ (Meyer, 1979), or be a constant (i.e., 5\%) fraction of the core radius (Kitchen and Zaneveld, 1992). The refractive index of the core was varied between 1.015 and 1.025, while that of the shell between 1.085 and 1.095 (Kitchen and Zaneveld, 1992). Thus, the volume-averaged refractive indices had median values of 1.05 (range: 1.047-1.057) and 1.03 (range: 1.025-1.035), for the first and second type of coated models, respectively. Particles were considered nonabsorbing. This analysis revealed that the resulting $\chi_{p}$ values around $117^{\circ}$ were consistent with the values obtained from the homogeneous spherical model (Fig. 3). On the other hand, the median backscattering ratio derived from the coated-sphere model with shell thickness of $75 \mathrm{~nm}$ was 0.011 (range: 0.0063-0.0180), while that for the coated-sphere model with shell thickness equal to $5 \%$ of the core radius was 0.0085 (range: 0.0064-0.0180). Thus, the backscattering ratios were about a factor 2.2 and 1.7 , respectively, larger than those derived from the homogeneous spherical model (median: 0.005, range: 0.0035-0.0074) using the same size distributions and refractive index equal to 1.05. In conclusion, it appears that the $\chi_{p}$ value adopted in this study is consistent with non-homogeneous models of phytoplankton cells that produce relatively large $b_{b p}: b_{p}$ ratios. It should be noted, though, that different combinations of shell thickness and refractive indices may produce significantly different backscattering ratios (both higher and lower). A thorough investigation of the optimal coated shell model for phytoplankton, however, is beyond the scope of this work.

Acknowledgements. The authors would like to thank the captain and crew of the R. V. Ka'imi Moana for making this study possible. WET Labs is kindly acknowledged for providing the technical drawings used for designing the flow-through backscattering chamber and for assistance in operating the BB3 meter. C. Roesler kindly provided the HTSRB used for in this study. R. O'Malley is acknowledged for providing the MODIS AQUA chl- $a$ estimates. Many thanks to C. Mätzler and X. Zhang for providing codes for modeling coated spheres and $\beta_{s w}$. NASA funding is acknowledged under contracts NNG05GD18G, NNG05GD16G, and NNG05GR50G to M. J. B. Finally, the authors would like to thank D. Stramski and M. Twardowski for their critical comments that considerably improved the manuscript.

Edited by: L. Bopp

\section{References}

Aas, E.: Refractive index of phytoplankton derived from its metabolite composition, J. Plankton Res., 18, 2223-2249, 1996.

Ahn, Y., Bricaud, A., and Morel, A.: Light backscattering efficiency and related properties of some phytoplankters, Deep-Sea Res., 38, 1835-1855, 1992.

Behrenfeld, M. J. and Boss, E.: The beam attenuation to chlorophyll ratio: an optical index of phytoplankton physiology in the surface ocean?, Deep-Sea Res. Pt. I, 50, 1537-1549, 2003. 
Behrenfeld, M. J. and Boss, E.: Beam attenuation and chlorophyll concentration as alternative optical indices of phytoplankton biomass, J. Mar. Res., 64, 431-451, 2006.

Behrenfeld, M. J., Boss, E., Siegel, D. A., and Shea, D. M.: Carbon-based ocean productivity and phytoplankton physiology from space, Global Biogeochem. Су., 19, 1-14, doi:10.1029/2004GB002 299, 2005.

Bernard, S., Probyn, T. A., and Quirantes, A.: Simulating the optical properties of phytoplankton cells using a two-layered spherical geometry, Biogeosciences Discuss., 6, 1497-1563, 2009, http://www.biogeosciences-discuss.net/6/1497/2009/.

Berthon, J. F., Shybanov, E., Lee, M. E. G., and Zibordi, G.: Measurements and modeling of the volume scattering function in the coastal northern Adriatic Sea, Appl. Optics, 46, 5189-5203, 2007.

BIPM and ISO: Guide to the expression of uncertainty in measurement, International Organization for Standardization, Geneve, Switzerland, 1995.

Bohren, C. F. and Huffman, D. R.: Absorption and scattering of light by small particles, Wiley, New York, 1983.

Bohren, C. F. and Singham, S. B.: Backscattering by nonspherical particles - A review of methods and suggested new approaches, J. Geophys. Res.-Atmos., 96, 5269-5277, 1991.

Boss, E. and Pegau, W. S.: Relationship of light scattering at an angle in the backward direction to the backscattering coefficient, Appl. Optics, 40, 5503-5507, 2001.

Boss, E., Twardowski, M. S., and Herring, S.: Shape of the particulate beam attenuation spectrum and its inversion to obtain the shape of the particulate size distribution, Appl. Optics, 40, 48854893, 2001.

Boss, E., Slade, W. H., Behrenfeld, M., and Dall'Olmo, G.: Acceptance angle effects on the beam attenuation in the ocean, Opt. Express, 17, 1535-1550, 2009.

Boss, E. S., Collier, R., Larson, G., Fennel, K., and Pegau, W. S.: Measurements of spectral optical properties and their relation to biogeochemical variables and processes in Crater Lake, Crater Lake National Park, OR, Hydrobiologia, 574, 149-159, 2007.

Breneman, E.: Light trap of high-performance and simple construction, Appl. Optics, 20, 1118-1119, 1981.

Brown, O. B. and Gordon, H. R.: Size-refractive index distribution of clear coastal water particulates from light scattering, Appl. Optics, 13, 2874, 1974.

Carder, K. L., Tomlinso, R. D., and Beardsle, G. F.: Technique for estimation of indexes of refraction of marine phytoplankters, Limnol. Oceanogr., 17, 833-839, 1972.

Chami, M., Marken, E., Stamnes, J. J., Khomenko, G., and Korotaev, G.: Variability of the relationship between the particulate backscattering coefficient and the volume scattering function measured at fixed angles, J. Geophys. Res.-Oceans, 111, 1-10, doi:10.1029/2005JC003 230, 2006.

Chang, G. C., Dickey, T. D., Mobley, C. D., Boss, E., and Pegau, W. S.: Toward closure of upwelling radiance in coastal waters, Appl. Optics, 42, 1574-1582, 2003.

Chavez, F. P., Buck, K. R., Bidigare, R. R., Karl, D. M., Hebel, D., Latasa, M., Campbell, L., and Newton, J.: On the chlorophyll-a retention properties of glass-fiber GF/F filters, Limnol. Oceanogr., 40, 428-433, 1995.

Chung, S. P., Gardner, W. D., Richardson, M. J., Walsh, I. D., and Landry, M. R.: Beam attenuation and micro-organisms: Spatial and temporal variations in small particles along 140 degrees W during the 1992 JGOFS EqPac transects, Deep-Sea Res. Pt. II, 43, 1205-1226, 1996.

Chung, S. P., Gardner, W. D., Landry, M. R., Richardson, M. J., and Walsh, I. D.: Beam attenuation by microorganisms and detrital particles in the equatorial Pacific, J. Geophys. Res.-Oceans, 103, 12669-12681, 1998.

Ciotti, A. M., Lewis, M. R., and Cullen, J. J.: Assessment of the relationships between dominant cell size in natural phytoplankton communities and the spectral shape of the absorption coefficient, Limnol. Oceanogr., 47, 404-417, 2002.

Clarke, A. and Leakey, R. J. G.: The seasonal cycle of phytoplankton, macronutrients, and the microbial community in a nearshore Antarctic marine ecosystem, Limnol. Oceanogr., 41, 1281-1294, 1996.

Claustre, H., Morel, A., Babin, M., Cailliau, C., Marie, D., Marty, J. C., Tailliez, D., and Vaulot, D.: Variability in particle attenuation and chlorophyll fluorescence in the tropical Pacific: Scales, patterns, and biogeochemical implications, J. Geophys. Res.-Oceans, 104, 3401-3422, 1999.

Clavano, W. R., Boss, E., and Karp-Boss, L.: Inherent optical properties of non-spherical marine-like particles from theory to observation, Oceanogr. Mar. Biol., 45, 1-38, 2007.

Cole, J. J., Findlay, S., and Pace, M. L.: Bacterial production In fresh and saltwater ecosystems - A cross-system overview, Mar. Ecol.-Prog. Ser., 43, 1-10, 1988.

Droppo, I. G.: Encyclopedia of analytical chemistry, chap. Filtration in Particle Size Analysis, 5397-5413, John Wiley \& Sons Ltd, Chichester, 2000.

Durand, M. D. and Olson, R. J.: Contributions of phytoplankton light scattering and cell concentration changes to diel variations in beam attenuation in the equatorial Pacific from flow cytometric measurements of pico-, ultra- and nanoplankton, Deep-Sea Res. Pt. II, 43, 891-906, 1996.

DuRand, M. D., Green, R. E., Sosik, H. M., and Olson, R. J.: Diel variations in optical properties of Micromonas pusilla (Prasinophyceae), J. Phycol., 38, 1132-1142, 2002.

Gardner, W. D., Mishonov, A., and Richardson, M. J.: Global POC concentrations from in-situ and satellite data, Deep-Sea Res. Pt. II, 53, 718-740, 2006.

Gasol, J. M. and Duarte, C. M.: Comparative analyses in aquatic microbial ecology: how far do they go?, Fems Microbiol. Ecol., 31, 99-106, 2000.

Geider, R. J., MacIntyre, H. L., and Kana, T. M.: A dynamic regulatory model of phytoplanktonic acclimation to light, nutrients, and temperature, Limnol. Oceanogr., 43, 679-694, 1998.

Glover, H., Prezelin, B., Campbell, L., Wyman, M., and Garside, C.: A nitrate-dependent Synechococcus bloom in surface Sargasso Sea water, Nature, 331, 161-163, 1988.

Gordon, H. R.: Normalized water-leaving radiance: revisiting the influence of surface roughness, Appl. Optics, 44, 241-248, 2005.

Green, R. E., Sosik, H. M., and Olson, R. J.: Contributions of phytoplankton and other particles to inherent optical properties in New England continental shelf waters, Limnol. Oceanogr., 48, 2377-2391, 2003.

Grob, C., Ulloa, O., Claustre, H., Huot, Y., Alarcón, G., and Marie, D.: Contribution of picoplankton to the total particulate organic carbon concentration in the eastern South Pacific, Biogeosciences, 4, 837-852, 2007, 
http://www.biogeosciences.net/4/837/2007/.

Hooker, S. B., Claustre, H., Ras, J., Van Heukelem, L., Berthon, J.-F., Targa, C., van der Linde, D., Barlow, R., and Session, H.: The first SeaWiFS HPLC analysis round-robin experiment (SeaHARRE-1), NASA Technical Memorandum - SeaWIFS Postlaunch Technical Report Series no. 14, 40-42, 2000.

Hulst van de, H. C.: Light scattering by small particles, Wiley, New York, 1957.

Huot, Y., Babin, M., Bruyant, F., Grob, C., Twardowski, M. S., and Claustre, H.: Relationship between photosynthetic parameters and different proxies of phytoplankton biomass in the subtropical ocean, Biogeosciences, 4, 853-868, 2007, http://www.biogeosciences.net/4/853/2007/.

Huot, Y., Morel, A., Twardowski, M. S., Stramski, D., and Reynolds, R. A.: Particle optical backscattering along a chlorophyll gradient in the upper layer of the eastern South Pacific Ocean, Biogeosciences, 5, 495-507, 2008, http://www.biogeosciences.net/5/495/2008/.

Kitchen, J. C. and Zaneveld, J. R. V.: A three-layered sphere model of the optical properties of phytoplankton, Limnol. Oceanogr., 37, 1680-1690, 1992.

Knefelkamp, B., Carstens, K., and Wiltshire, K. H.: Comparison of different filter types on chlorophyll-a retention and nutrient measurements, J. Exp. Mar. Biol. Ecol., 345, 61-70, 2007.

Logan, B. E.: Theoretical analysis of size distributions determined with screens and filters, Limnol. Oceanogr., 38, 372-381, 1993.

Logan, B. E., Passow, U., and Alldredge, A. L.: Variable retention of diatoms on screens during size separations, Limnol. Oceanogr., 39, 390-395, 1994.

Loisel, H. and Morel, A.: Light Scattering and Chlorophyll Concentration in Case 1 Waters: a Reexamination, Limnol. Oceanogr., 43, 847-858, 1998.

MacIntyre, H. L., Kana, T. M., Anning, T., and Geider, R. J.: Photoacclimation of photosynthesis irradiance response curves and photosynthetic pigments in microalgae and cyanobacteria, J. Phycol., 38, 17-38, 2002.

Mahowald, N., Kohfeld, K., Hansson, M., Balkanski, Y., Harrison, S. P., Prentice, I. C., Schulz, M., and Rodhe, H.: Dust sources and deposition during the last glacial maximum and current climate: A comparison of model results with paleodata from ice cores and marine sediments, J. Geophys. Res.-Atmos., 104, 15895-15916, 1999.

Meyer, R. A.: Light-scattering from biological cells - Dependence of backscatter radiation on membrane thickness and refractiveindex, Appl. Optics, 18, 585-588, 1979.

Mobley, C. D., Sundman, L. K., and Boss, E.: Phase function effects on oceanic light fields, Appl. Optics, 41, 1035-1050, 2002.

Moore, C., Twardowski, M., and Zaneveld, J.: The ECO VSF: A multi-angle scattering sensor for determination of the volume scattering function in the backward direction, in: Ocean Optics XV, 16-20, SPIE, Office of Naval Research, 2000.

Morel, A. and Ahn, Y. H.: Optics of heterotrophic nanoflagellates and ciliates - a tentative assessment of their scattering role in oceanic waters compared to those of bacterial and algal cells, J. Mar. Res., 49, 177-202, 1991.

Morel, A. and Maritorena, S.: Bio-pptical properties of oceanic waters: a reappraisal, J. Geophys. Res.-Oceans, 106, 7163-7180, 2001.

Morel, A., Antoine, D., and Gentili, B.: Bidirectional reflectance of oceanic waters: accounting for raman emission and varying particle scattering phase function, Appl. Optics, 41, 6289-6306, 2002.

Nelson, N. B., Carlson, C. A., and Steinberg, D. K.: Production of chromophoric dissolved organic matter by Sargasso Sea microbes, Mar. Chem., 89, 273-287, 2004.

Oubelkheir, K. J., Claustre, H., Sciandra, A., and Babin, M.: Bio-Optical and Biogeochemical Properties of Different Trophic Regimes in Oceanic Waters, Limnol. Oceanogr., 50, 1795-1809, 2005.

Pope, R. M. and Fry, E. S.: Absorption spectrum (380-700 nm) of pure water. 2. Integrating cavity measurements, Appl. Optics, 36, 8710-8723, 1997.

Quinby-Hunt, M. S., Hunt, A. J., Lofftus, K., and Shapiro, D.: Polarized-Light Scattering Studies of Marine Chlorella, Limnol. Oceanogr., 34, 1587-1600, 1989.

Quirantes, A. and Bernard, S.: Light scattering by marine algae: two-layer spherical and nonspherical models, J. Quant. Spectrosc. Ra., 89, 311-321, 2004.

Quirantes, A. and Bernard, S.: Light-scattering methods for modelling algal particles as a collection of coated and/or nonspherical scatterers, J. Quant. Spectrosc. Ra., 100, 315-324, 2006.

Roesler, C. and Boss, E.: Real-time coastal observing systems for marine ecosystem dynamics and harmful algal blooms: theory, instrumentation and modelling, chap. In situ measurement of the inherent optical properties and potential for harmful algal bloom detection and coastal ecosystem observations, 153-206, UNESCO, 2008.

Sheldon, R. W.: Size separation of marine seston by membrane and glass-fiber filters, Limnol. Oceanogr., 17, 494-498, 1972.

Siegel, D., Dickey, T., Washburn, L., Hamilton, M., and Mitchell, B.: Optical determination of particulate abundance and production variations in the oligotrophic ocean, Deep-Sea Res., 36, 211-222, 1989.

Siegel, D. A., Maritorena, S., Nelson, N. B., and Behrenfeld, M. J.: Independence and interdependencies among global ocean color properties: Reassessing the bio-optical assumption, J. Geophys. Res.-Oceans, 110, C07011, doi:10.1029/2004JC002527, 2005.

Stramski, D. and Kiefer, D.: Light scattering by microorganisms in the open ocean, Prog. Oceanogr., 28, 343-383, 1991.

Stramski, D. and Morel, A.: Optical-properties of photosynthetic picoplankton in different physiological states as affected by growth irradiance, Deep-Sea Res., 37, 245-266, 1990.

Stramski, D. and Piskozub, J.: Estimation of scattering error in spectrophotometric measurements of light absorption by aquatic particles from three-dimensional radiative transfer simulations, Appl. Optics, 42, 3634-3646, 2003.

Stramski, D. and Reynolds, R. A.: Diel Variations in the OpticalProperties of a Marine Diatom, Limnol. Oceanogr., 38, 13471364, 1993.

Stramski, D., Reynolds, R. A., Kahru, M., and Mitchell, B. G.: Estimation of particulate organic carbon in the ocean from satellite remote sensing, Science, 285, 239-242, 1999.

Stramski, D., Boss, E., Bogucki, D., and Voss, K. J.: The role of seawater constituents in light backscattering in the ocean, Prog. Oceanogr., 61, 27-56, 2004.

Stramski, D., Reynolds, R. A., Babin, M., Kaczmarek, S., Lewis, M. R., Rttgers, R., Sciandra, A., Stramska, M., Twardowski, M S., Franz, B. A., and Claustre, H.: Relationships between the sur- 
face concentration of particulate organic carbon and optical properties in the eastern South Pacific and eastern Atlantic Oceans, Biogeosciences, 5, 171-201, 2008, http://www.biogeosciences.net/5/171/2008/.

Strickland, J. and Parsons, T.: A practical handbook of seawater analysis, Fisheries Research Board of Canada, 1972.

Sullivan, J. M., Twardowski, M. S., Donaghay, P. L., and Freeman, S. A.: Use of optical scattering to discriminate particle types in coastal waters, Appl. Optics, 44, 1667-1680, 2005.

Sullivan, J. M., Twardowski, M. S., Zaneveld, J. R. V., Moore, C. M., Barnard, A. H., Donaghay, P. L., and Rhoades, B.: Hyperspectral temperature and salt dependencies of absorption by water and heavy water in the $400-750 \mathrm{~nm}$ spectral range, Appl. Optics, 45, 5294-5309, 2006.

Twardowski, M. S., Boss, E., Macdonald, J. B., Pegau, W. S., Barnard, A. H., and Zaneveld, J. R. V.: A model for estimating bulk refractive index from the optical backscattering ratio and the implications for understanding particle composition in case $\mathrm{i}$ and case ii waters, J. Geophys. Res.-Oceans, 106, 14129-14142, 2001.

Twardowski, M. S., Claustre, H., Freeman, S. A., Stramski, D., and Huot, Y.: Optical backscattering properties of the "clearest" natural waters, Biogeosciences, 4, 1041-1058, 2007, http://www.biogeosciences.net/4/1041/2007/.

Vaillancourt, R. D., Brown, C. W., Guillard, R. R. L., and Balch, W. M.: Light backscattering properties of marine phytoplankton: relationships to cell size, chemical composition and taxonomy, J. Plankton Res., 26, 191-212, 2004.

Van Heukelem, L. and Thomas, C. S.: Computer-assisted highperformance liquid chromatography method development with applications to the isolation and analysis of phytoplankton pigments, J. Chromatogr. A, 910, 31-49, 2001.
Volten, H., de Haan, J. F., Hovenier, J. W., Schreurs, R., Vassen, W., Dekker, A. G., Hoogenboom, H. J., Charlton, F., and Wouts, R.: Laboratory measurements of angular distributions of light scattered by phytoplankton and silt, Limnol. Oceanogr., 43, 11801197, 1998.

Westberry, T., Behrenfeld, M., Siegel, D., and Boss, E.: Carbon-based primary productivity modeling with vertically resolved photophysiology, Global Biogeochem. Cy., 22, GB2024, doi:10.1029/2007GB003078, 2008.

Whitmire, A. L., Boss, E., Cowles, T. J., and Pegau, W. S.: Spectral variability of the particulate backscattering ratio, Opt. Express, 15, 7019-7031, 2007.

Zaneveld, J. and Pak, H.: Method for determination of index of refraction of particles suspended in ocean - Reply, J. Opt. Soc. Am., 63, 321-324, 1973.

Zaneveld, J. R. V., Kitchen, J. C., and Moore, C. C.: Scattering error correction of reflecting tube absorption meters, in: Ocean Optics XII, edited by: Ackelson, S., Vol. 2258, 44-55, SPIE, 1994.

Zhang, X. and Hu, L.: Estimating scattering of pure water from density fluctuation of the refractive index, Opt. Express, 17, 16711678, 2009.

Zhang, X., Hu, L., and He, M.-X.: Scattering by pure seawater: Effect of salinity, Opt. Express, 17, 5698-5710, 2009.

Zielinski, K., Król, T., Gedziorowska, D., and Wolinski, L.: Theoretical and experimental investigations into light scattering by the Chlorella vulgaris cell, Bulletin of the Polish Academy of Sciences, Earth Sci., 34, 313-319, 1986.

Zielinski, K., Król, T., and Gedziorowska, D.: The influence of the inner structure of the Chlorella vulgaris cell on light scattering properties, Bulletin of the Polish Academy of Sciences, Earth Sci., 35, 119-125, 1987. 